\title{
Dimensionamento e Simulação de Condensador Tipo Casco e Tubo Aletado Operando com Nanofluidos
}

\section{Design and Simulation of Finned Shell and Tube Condenser Operating with Nanofluids}

Área de Concentração

Engenharia Mecânica, Projeto de Sistemas

Térmicos, Trocadores de Calor

Aluno

Marcos Alexandre Izidoro da Fonseca

Orientador

José Alberto dos Reis Parise

Rio de Janeiro, Junho de 2016 
Marcos Alexandre Izidoro da Fonseca

\begin{abstract}
Dimensionamento e Simulação de Condensador Tipo Casco e Tubo Aletado Operando com Nanofluidos
\end{abstract}

PROJETO DE GRADUAÇÃO

\title{
DEPARTAMENTO DE ENGENHARIA MECÂNICA \\ Programa de Graduação em Engenharia Mecânica
}

Rio de Janeiro, Junho de 2016 
Marcos Alexandre Izidoro da Fonseca

\section{Dimensionamento e Simulação de Condensador tipo Casco e} Tubo Aletado Operando com Nanofluidos

\section{PROJETO DE GRADUÇÃO}

Projeto apresentado como requisito para obtenção do grau de Bacharel pelo Programa de Graduação em Engenharia Mecânica do Departamento de Engenharia Mecânica da PUC-Rio.

Orientador

José Alberto dos Reis Parise

Rio de Janeiro, Junho de 2016 


\section{Agradecimentos}

Agradeço primeiramente, e acima de tudo, a Deus. Agradeço pelo dom de sua infinita graça, sabendo que dela não sou digno.

Agradeço a minha família, pelo apoio incondicional e incentivo durante essa jornada. Em especial a minha mãe Alvira pelo esforço incansável durante toda minha vida, e irmã Marcia por estar sempre presente. Ao meu falecido pai, agradeço pelos breves momentos de sua companhia.

Ao meu orientador Prof. José Alberto dos Reis Parise, agradeço por poder receber um pouco do seu imenso conhecimento, além de agradecer pela costumeira disponibilidade e imensa boa vontade durante o meu curso de graduação e na orientação deste projeto.

À minha namorada Ana, agradeço pela companhia, apoio e motivação para o cumprimento dos meus objetivos.

Finalmente, agradeço aos meus verdadeiros amigos, com os quais pude cultivar a amizade durante esse tempo na PUC-Rio. 


\section{Resumo}

No presente trabalho, avaliou-se o comportamento e principais propriedades de um sistema trocador de calor quando operado com diferentes fluidos de trabalho. Inicialmente foi considerado a água, que posteriormente foi substituída por nanofluidos. Neste intuito, foi necessário aprimorar e simular através do software EES, um modelo matemático preexistente, que avalia as características térmicas e hidráulicas de um trocador de calor e também uma sub-rotina para a modelagem das características termofísicas dos nanofluidos. Os dados de entrada do modelo, referentes ao ponto de entrada do condensador, são: vazão mássica e temperatura do fluido de trabalho, pressão de condensação, temperatura e vazão mássica do refrigerante. Para avaliação de outros fluidos de trabalho, foi necessário aprimorar o modelo para o trocador de calor e utilizar uma sub-rotina que forneça as propriedades termofísicas dos nanofluidos para as simulações. Para os casos simulados, alterou-se os tipos de nanopartículas utilizadas para a composição do nanofluido, bem como a concentração volumétrica das mesmas. As nanopartículas consideradas foram compostas por óxido de alumínio, dióxido de titânio e cobre, com diâmetro de $10 \mathrm{~nm}$. A variação da concentração volumétrica das nanopartículas foi entre 0 e $1 \%$, incrementando-se $0,1 \%$ a cada novo caso avaliado. Considerando-se essa variação da concentração das nanopartículas para composição dos nanofluidos, nos resultados foram avaliadas as principais propriedades termofísicas dos nanofluidos utilizados. Sobre o condensador foram analisadas a taxa total de transferência de calor e a queda de pressão total no lado da água e nanofluidos.

\section{Palavras-Chave}

Nanofluidos; Dimensionamento; Simulação; Trocador de Calor; Condensador; Casco e Tubo; 


\begin{abstract}
In this study, the behavior and main properties of a heat exchanger was evaluated when operated with different working fluids. It was first considered as the water, which was later replaced by nanofluids. For this it was necessary to improve and simulate through the ESS software, a pre-existing mathematical model that evaluates the thermal and hydraulic characteristics of a heat exchanger and also a subroutine for the modeling of thermo-physical characteristics of nanofluids. The model input data relating to the condenser inlet point, are mass flow and temperature of the working fluid, condensing pressure, temperature and mass flow of the coolant. For evaluation of other working fluids, it was necessary to improve the model for the heat exchanger and use a subroutine to provide the thermo-physical properties of nanofluids for the simulations. For the simulated cases changed the types of nanoparticles used for nanofluid composition and the volume concentration. The nanoparticles were considered to consist of aluminum oxide, titanium dioxide and copper, with a diameter of $10 \mathrm{~nm}$. The variation of the volume concentration of the nanoparticles is between 0 and $1 \%$, increasing by $0.1 \%$ for each new case evaluated. Considering the variation of the concentration of the nanoparticles in the composition of nanofluids, the results were evaluated the main termo-physical properties of nanofluids used. About condenser analyzed the total rate of heat transfer and the total pressure drop across the water side and nanofluids.
\end{abstract}

\title{
Keywords
}

Nanofluids; Design; Simulation; Heat Exchanger; Condenser; Shell and Tube 


\section{Sumário}

1. Introdução ……………………………………………………………………....

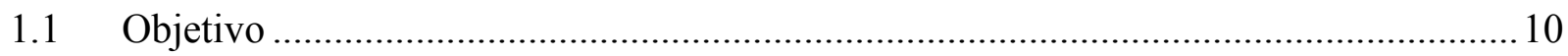

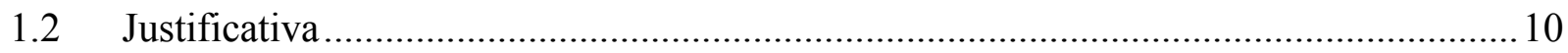

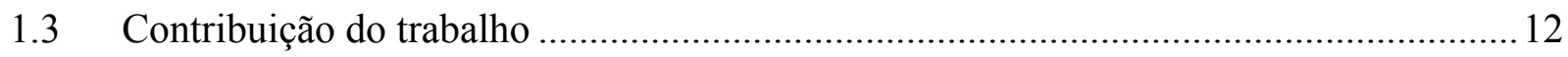

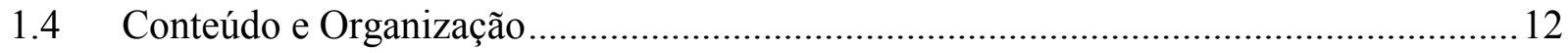

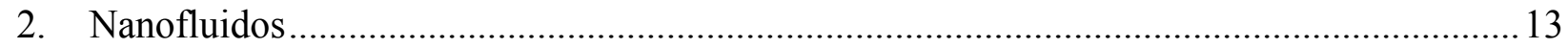

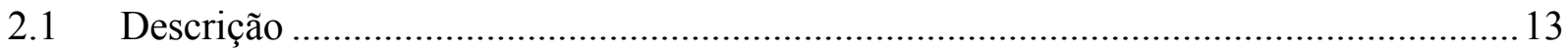

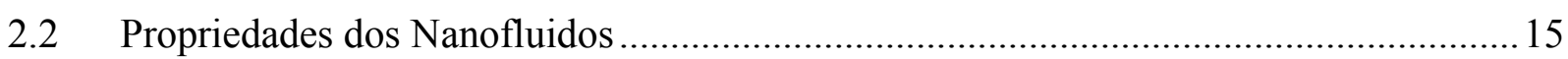

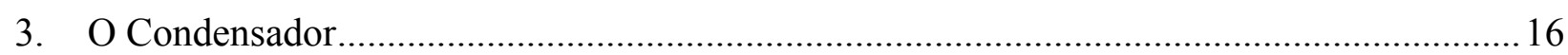

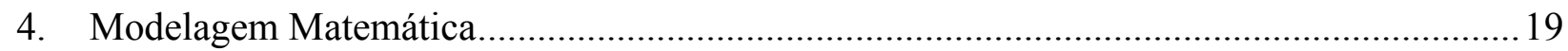

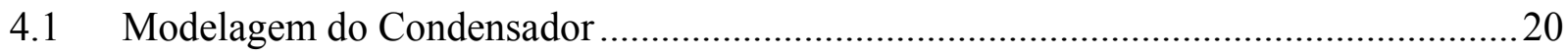

4.2 Zona de Dessuperaquecimento mais Bifásica ……………………………………........ 21

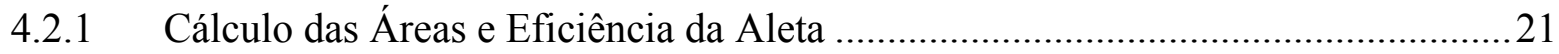

4.2.2 Cálculo do Coeficiente Convectivo do Refrigerante............................................2

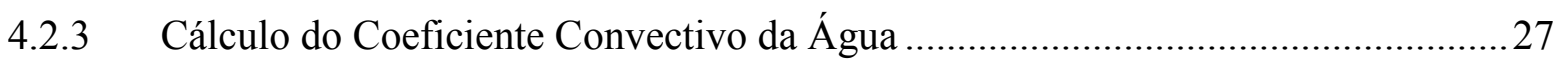

4.2.4 Cálculo da Temperatura Média da Parede Externa do Tubo ………………….......28

4.2.5 Cálculo do Coeficiente Global de Troca de Calor e da Efetividade .......................29

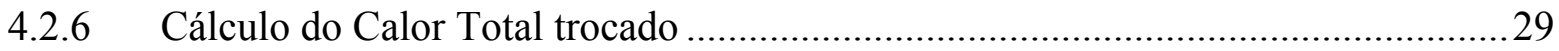

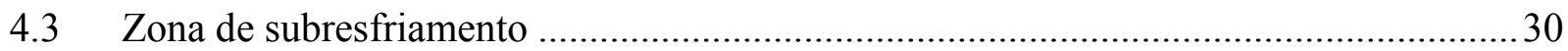

4.3.1 Cálculo do Coeficiente Convectivo do Refrigerante................................................30

4.3.2 Cálculo do Coeficiente Global de Troca de Calor da Zona Subresfriada ...............32

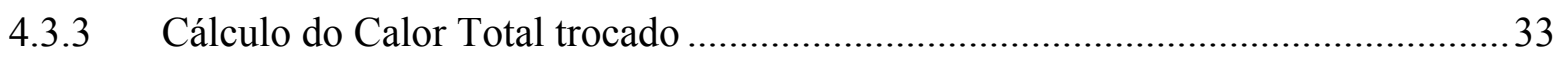

4.4 Calor Total Trocado pelo Condensador....................................................................... 34

4.5 Queda de Pressão no Condensador................................................................................34

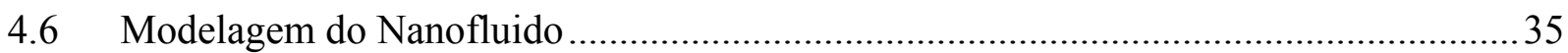

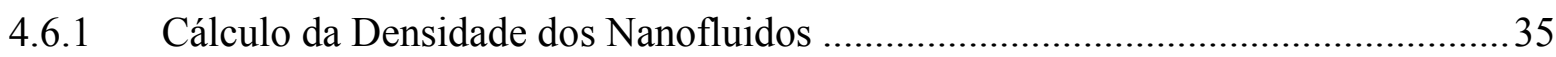

4.6.2 Cálculo da Viscosidade dos Nanofluidos.................................................................. 35

4.6.3 Cálculo do Calor Específico dos Nanofluidos ............................................................36

4.6.4 Cálculo da Condutividade Térmica dos Nanofluidos ...............................................36

4.6.5 Cálculo do Número de Prandtl dos Nanofluidos...................................................... 37

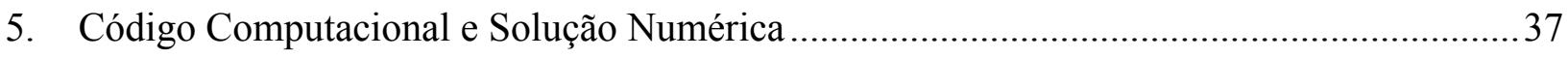




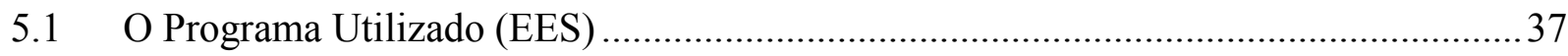

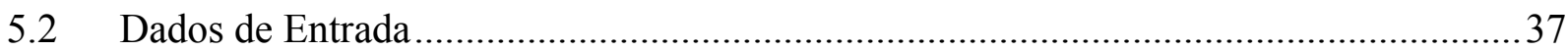

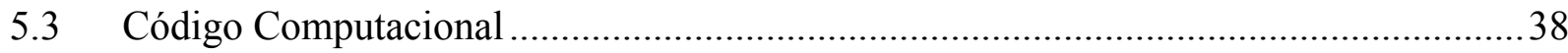

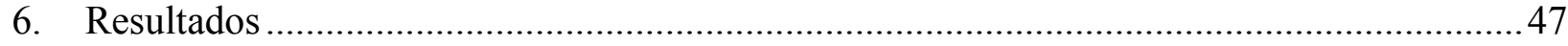

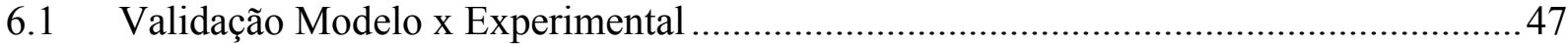

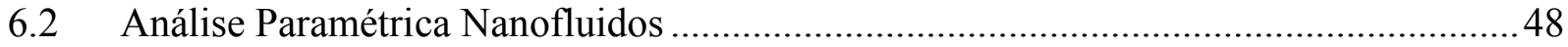

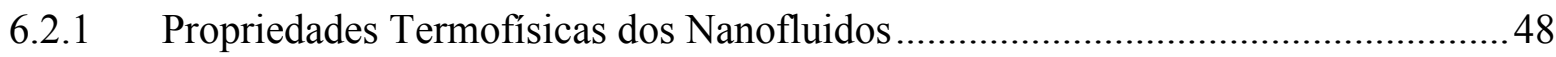

6.2.2 Taxa de transferência de calor no Condensador........................................................ 50

6.2.3 Queda de Pressão no Condensador .......................................................................... 51

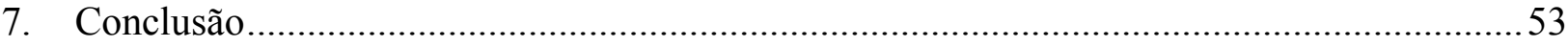

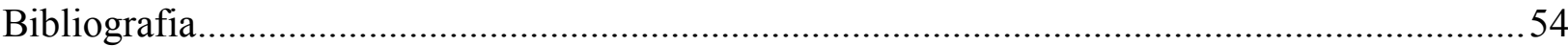

\section{LISTA DE FIGURAS}

Figura 2.1 - Condut. térmica elementos x condut. térmica da água (Campos et al, 2009) ........... 12

Figura 2.2 - Nanopartículas de 79\% A12O3 - 21\% H2O (Hosokawa et al., 2007) ..................... 14

Figura 3.1 - Pontos termodinâmicos do condensador ............................................................. 16

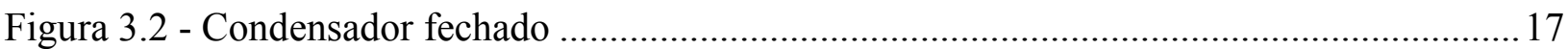

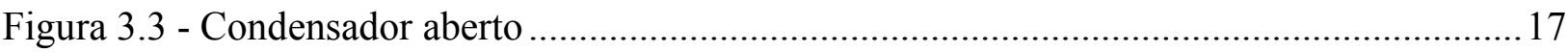

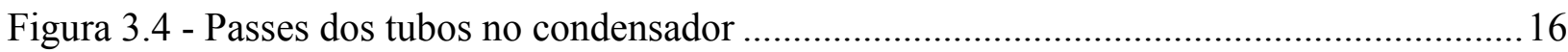

Figura 3.5 - Escoamento dos fluidos no condensador........................................................... 16

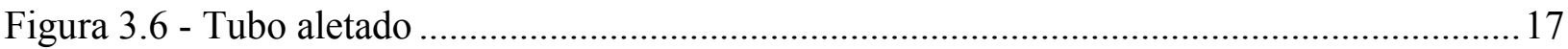

Figura 3.7 - Evolução das temperaturas dos fluidos ao longo do processo ................................. 18

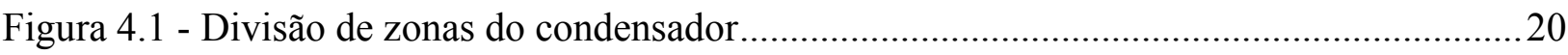

Figura 4.2 - Modelo da área unitária no lado do refrigerante ................................................. 20

Figura 4.3 - Esquema da geometria da área entre os tubos .................................................. 21

Figura 4.4 - Parâmetros geométricos de uma aleta circular ................................................... 22

Figura 5.1 - Gráfico comparativo da taxa de calor trocada no condensador................................ 46

Figura 6.1 - Gráfico de Resultado: Densidade dos Nanofluidos .................................................. 47

Figura 6.2 - Gráfico de Resultado: Viscosidade dos Nanofluidos .............................................. 47

Figura 6.3 - Gráfico de Resultado: Calor Específico dos Nanofluidos ....................................... 48

Figura 6.4 - Gráfico de Resultado: Condutividade Térmica dos Nanofluido ..............................48

Figura 6.5 - Gráfico de Resultado: Taxa de Transferência de Calor, vazão mássica constante.... 49

Figura 6.6 - Gráfico de Resultado: Taxa de Transferência de Calor, velocidade constante ......... 49

Figura 6.7 - Gráfico de Resultado: Taxa de Transferência de Calor, Reynolds contante ............. 50

Figura 6.8 - Gráfico de Resultado: Queda de Pressão, vazão mássica constante ......................... 50

Figura 6.9 - Gráfico de Resultado: Queda de Pressão, velocidade constante ............................... 51

Figura 7.0 - Gráfico de Resultado: Queda de Pressão, Reynolds constante .................................51 


\section{LISTA DE TABELAS}

Tabela 2.1 - Propriedades termofísicas de nanopartículas e fluidos base .................................. 14

Tabela 3.1 - Características nominais do condensador ............................................................ 16

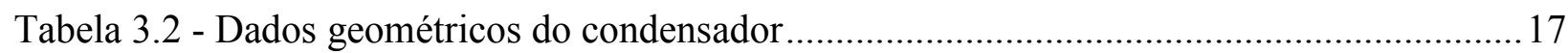

Tabela 4.1 - Correlações para fluxo cruzado sobre tubos, para $\mathrm{N}>16$ e $0,7<\operatorname{Pr}<500$. ( $\mathrm{P}_{\mathrm{p}} \mathrm{e}$

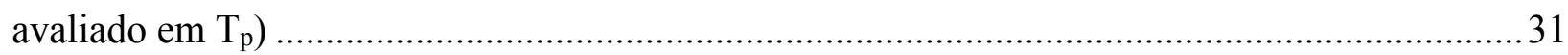

Tabela 4.2 - Fator de correção proposto por Zukauskas (1987) ................................................... 31

Tabela 5.1 - Tabela Paramétrica com dados de entrada e saída .................................................476 


\section{Introdução}

Considerando nosso modelo de vida contemporâneo, é possível notar que é elevada e crescente a demanda por bens de consumo que cumpram a finalidade de suprir nossas necessidades básicas e contribuir para o aumento da comodidade e conforto em nosso cotidiano. Partindo deste princípio, é notório que obrigatoriamente nossos meios de produção são rotineiramente impactados por essa demanda. O aumento da eficiência energética, e a redução dos custos dos processos compreendidos nos mais diversos meios de produção, é de vital importância para a manutenção da produção em números que atendam a demanda atual. Além de fatores econômicos envolvidos, este aumento de eficiência tão necessário, pode ser considerado como um dos principais gargalos na produção de um determinado bem.

São inúmeros os processos industriais onde estão presentes os sistemas de troca térmica. Desde a complexa indústria do petróleo, até simples trocadores de calor para sistemas de refrigeração residencial, percebemos a importância destes sistemas. Como introduzido, é pujante a necessidade do desenvolvimento de novas alternativas que possam contribuir para o aumento de sua eficiência, contribuindo assim para o aumento da eficiência global do processo como um todo.

É neste contexto que o presente trabalho se desenvolve: avaliar o desempenho de uma alternativa para o aumento da eficiência de um sistema de refrigeração. A utilização de nanofluidos em sistemas de refrigeração é sem dúvida uma destas novas alternativas. Estes são constituídos pela combinação entre um fluido base convencionalmente utilizado em sistemas de trocadores de calor e partículas de tamanho manométrico. A esperada superioridade da capacidade de troca de calor que esta combinação de fluidos com nanopartículas possuí frente a capacidade de troca de calor de fluidos convencionais, gera grande interesse e motiva a busca pelo entendimento dos fenômenos decorrentes da utilização destes fluidos, bem como a validação da melhora de desempenho esperado. Em busca destes resultados, neste trabalho serão avaliadas as principais 
características comportamentais de um sistema de refrigeração do tipo casco e tubo aletado, substituindo a água por nanofluidos como fluido de refrigeração. Posteriormente variou-se a fração volumétrica das nanopartículas presentes nestes fluidos.

\subsection{Objetivo}

Este trabalho cumpre o objetivo de avaliar através de utilização dos recursos computacionais, com a simulação numérica, utilizando um modelo matemático preexistente, as principais características comportamentais e o desempenho de um sistema de refrigeração do tipo casco e tubo substituindo a água por nanofluidos como fluido de refrigeração.

Para tal, foram necessários os seguintes passos:

1. Aprimoramento e utilização de um modelo matemático para o trocador de calor considerado. Neste caso, um condensador do tipo casco e tudo;

2. Utilização de um modelo matemático que represente o comportamento dos nanofluidos utilizados e suas respectivas propriedades termofísicas;

3. Modelagem de processos físicos que regem o comportamento dos fluidos em um trocador de calor do tipo casco e tudo;

4. Análise e comparação dos resultados obtidos quando ocorre a troca entre os fluidos refrigerantes;

\subsection{Justificativa}

Considerando os principais fluidos utilizados em sistemas trocadores de calor, observamos que a principal limitação para o aumento da eficiência na troca de calor, por parte do fluido, reside na condutividade térmica dos mesmos (Choi et al., 1995). Naturalmente um fluido com maior capacidade de realizar troca térmica é altamente atrativo para qualquer das aplicações nas quais 
venha a ser utilizado. O ganho de eficiência do sistema, de um modo geral deve ser sempre buscado e será sempre bem-vindo.

Com a utilização dos nanofluidos, como fluido de trabalho em trocadores de calor é possível aumentar a eficiência global do sistema. Em teoria, o ganho de eficiência é obtido pelo incremento na condutividade térmica do fluido base após a adição das nanopartículas. Nas mais diversas aplicações podemos obter ganhos como por exemplo: redução da área total de troca do trocador de calor, redução da vazão de fluido de trabalho necessário para a mesma quantidade de calor trocado, entre outras (Choi et al., 2002).

Segundo Diamond (1995), as principais propriedades dos nanofluidos que o fazem ser considerados como possíveis candidatos como a próxima geração de fluidos de trabalho em sistemas trocadores de calor são:

1. Elevadas condutividades térmicas com respeito às tradicionais suspensões sólido/líquido atualmente disponíveis.

2. Não há uma relação linear entre a concentração e a condutividade térmica.

3. Há um incremento da condutividade térmica com a temperatura, na maioria dos casos.

4. Há incrementos significativos do fluxo de calor crítico (CHF).

Considerando que ainda existem diversos fatores a serem analisados, simulados e avaliados em experimentos sobre a utilização dos nanofluidos como fluido de trabalho nos mais diversos tipos de trocadores de calor, e também obter o mínimo de predição sobre o seu comportamento quando submetidos a simulação e avaliação em sistemas reais, o presente trabalho encontra sua principal justificativa. 


\subsection{Contribuição do trabalho}

O presente trabalho pretende contribuir com o fornecimento de dados referente a simulação numérica e avaliação de resultados sobre o comportamento de nanofluidos diversos, quando utilizados como fluidos de trabalho em um trocador de calor do tipo caso e tubo sob determinada condição de operação.

\subsection{Conteúdo e Organização}

No segundo capitulo é apresentada uma introdução teórica sobre os nanofluidos, considerando suas principais características. No terceiro capítulo são explicitadas as características gerais do condensador a ser modelado, assim como seu funcionamento, dados geométricos e condições de operação. No quarto capítulo, é apresentado o modelo matemático utilizado, com todas as operações realizadas e relações termodinâmicas.

Logo em seguida, no quinto capítulo é descrita a solução numérica e seu código computacional, os quais permitirão a análise comparativa com os dados medidos em laboratório e a respectiva validação do modelo desenvolvido.

No sexto capítulo segue a análise paramétrica contendo os resultados retornados pelo modelo simulado e suas respectivas variações. No sétimo capítulo, segue a conclusão do trabalho. Após a conclusão é apresentada as referências bibliográficas utilizadas para a construção do presente trabalho. 


\section{Nanofluidos}

\subsection{Descrição}

Nanofluidos são misturas compostas por um fluido base e partículas de dimensões manométricas. Podem também ser definidos como suspensões de partículas de diâmetros entre 1 e $100 \mathrm{~nm}$ quando dispersadas em fluidos de trabalho convencionais, como por exemplo: água, óleo, entre outros (Das et al., 2008). O interesse pelo estudo da utilização destes fluidos como fluidos de trabalho em sistema de refrigeração por exemplo, surge devido a elevada capacidade de troca de calor que estes fluidos apresentam frente aos fluidos de trabalho convencionalmente utilizados. Esse incremento na troca térmica é devido, entre outros fatores, a elevada condutividade térmica dos elementos que dão origem as nanopartículas utilizadas nas suspensões.

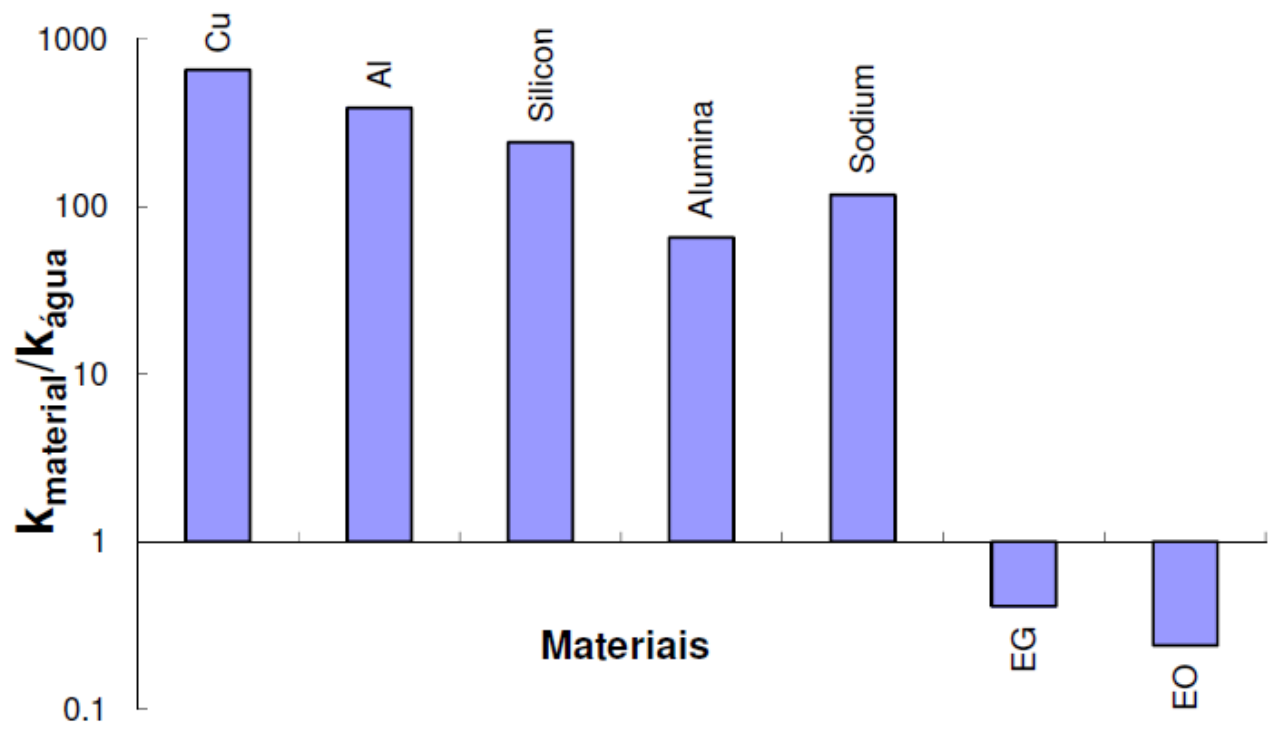

Figura 2.1 - Condutividade térmica elementos x condutividade térmica da água (Campos et al, 2009)

A relevância da sobre o uso destes fluidos, e o fato de que a suspensão de partículas sólidas em líquidos é capaz de provocar um incremento, muitas vezes significativo, na condutividade térmica da solução em relação ao fluido base, é conhecida e estudada a um tempo considerável (Witharana, 2003). 
Considerando os aspectos citados, atualmente estes fluidos são fortes candidatos a se tornarem a próxima geração de fluidos refrigerantes para as mais diversas aplicações devido as características favoráveis de transferência de calor que são obtidas através da deposição das partículas de tamanho manométrico em fluidos convencionais.

De acordo com Bandarra Filho et al. (2008) e Campos (2009), os aspectos de maior interesse na temática dos nanofluidos podem ser resumidos em:

1. Elevada condutividade térmica da suspensão, quando comparada aos fluidos convencionais;

2. Possibilidade do aumento ou diminuição do coeficiente de troca de calor da solução, com o aumento da fração volumétrica de nanopartículas, considerando escoamento com uma única fase;

3. Inexistência de uma tendência bem definida, incremento ou diminuição do coeficiente de troca de calor, quando existe ebulição no escoamento;

Segundo Das et al., (2008) é possível utilizar as seguintes nanopartículas para composição dos nanofluidos:

1. Óxidos cerâmicos $\left(\mathrm{Al}_{2} \mathrm{O}_{3}, \mathrm{CuO}\right)$.

2. Nitridos cerâmicos (AlN, SiN).

3. Cerâmicos a base de carbeto ( $\mathrm{SiC}, \mathrm{TiC})$.

4. Metais $(\mathrm{Cu}, \mathrm{Ag}, \mathrm{Au})$.

5. Semicondutores $\left(\mathrm{TiO}_{2}, \mathrm{SiC}\right)$.

6. Nanotubos de carbono. 
A nomenclatura é do nanofluido é derivado diretamente de sua composição, ou seja, do fluido base e do elemento utilizado para as nanopartículas. No caso do óxido de alumínio, de fórmula química $\mathrm{Al}_{2} \mathrm{O}_{3}$ suspenso em água $\left(\mathrm{H}_{2} \mathrm{O}\right)$, temos o nanofluido Óxido de Alumínio-Água ou então $\mathrm{Al}_{2} \mathrm{O}_{3}-\mathrm{H}_{2} \mathrm{O}$. Como ilustração segue uma micrografia de nanopartículas de Óxido de Alumínio-Água.

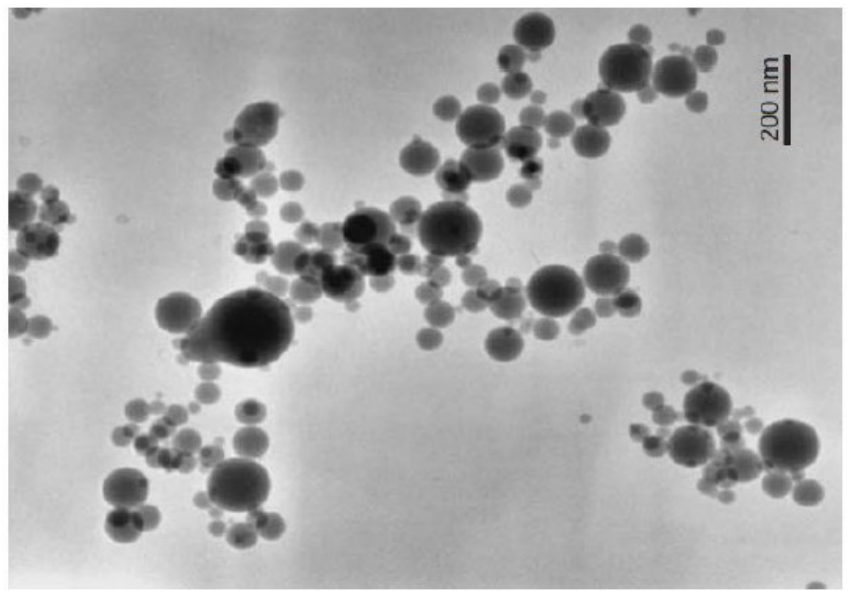

Figura 2.2 - Nanopartículas de 79\% $\mathrm{Al}_{2} \mathrm{O}_{3}-21 \% \mathrm{H}_{2} \mathrm{O}$ (Hosokawa et al., 2007)

\subsection{Propriedades dos Nanofluidos}

A determinação das principais propriedades dos nanofluidos utilizados no presente trabalho foram obtidas através da utilização de correlações encontradas obtidas na literatura. Tais correlações levam em consideração principalmente as propriedades termofísicas do fluido base e também das do elemento utilizado para geração das nanopartículas. Em Velagapudi et al., (2008) são encontradas tais propriedades. As equações foram listadas no item 4.5.

\begin{tabular}{|l|c|c|c|c|c|c|}
\hline \multicolumn{1}{|c|}{ Property } & Water & $\begin{array}{c}\text { Ethylene } \\
\text { glycol }\end{array}$ & $\mathrm{Cu}$ & $\mathrm{Al}_{2} \mathrm{O}_{3}$ & $\mathrm{CuO}$ & $\mathrm{TiO}_{2}$ \\
\hline$C[\mathrm{~J} / \mathrm{kgK}]$ & 4179 & 2415 & 385 & 765 & 535.6 & 686.2 \\
$\rho\left[\mathrm{kg} / \mathrm{m}^{3}\right]$ & 997.1 & 1111 & 8933 & 3970 & 6500 & 4250 \\
$k[\mathrm{~W} / \mathrm{mK}]$ & 0.605 & 0.252 & 400 & 40 & 20 & 8.9538 \\
$\alpha\left[\mathrm{m}^{2} / \mathrm{s}\right]$ & 1.47 & 93 & 1163 & 1317 & 57.45 & 30.7 \\
\hline
\end{tabular}

Tabela 2.1 - Propriedades termofísicas de nanopartículas e fluidos base 


\section{O Condensador}

O contexto considerado é o de um sistema de refrigeração o qual trabalha a altos níveis de temperatura e pressão no condensador. Na prática, os principais desafios técnicos são a alta temperatura na saída do compressor e o espaço reduzido de área transversal disponível para a condensação. Os modelos mais simplistas consideram as três zonas do condensador como um único grupo bifásico, onde apenas um coeficiente global de transferência de calor é calculado. Um modelo mais detalhado, determinístico, é utilizado no presente estudo, distingue duas diferentes zonas, uma representada pelo estado superaquecido e bifásico, e outra pelo subresfriado, identificando seus respectivos coeficientes de troca de calor.

Adiante seguem as características gerais do condensador a ser modelado, assim como seu funcionamento, dados geométricos e condições de operação. O condensador será simulado de modo a prever seu comportamento a partir dos dados empíricos obtidos por Pruzaesky (2005).

A Figura 3.1 abaixo, apresenta o esquema de pontos termodinâmicos experimentais para os dois fluidos envolvidos na troca de calor que ocorre no condensador. Na figura, a linha pontilhada delimita o volume de controle analisado nessa parte do trabalho.

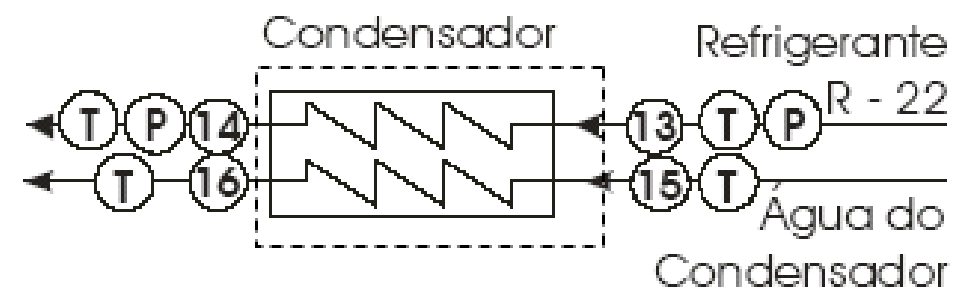

Figura 3.1 - Pontos termodinâmicos do condensador

O condensador é um trocador de calor do tipo casco e tubo aletado, da marca $E V A C O N^{\circledR}$, modelo $C F A-2$, com 5 fileiras de tubos escalonadas (desalinhadas). O condensador em questão é mostrado na Figura 3.2. Abaixo, Tabela $3.1 \mathrm{com}$ as características nominais do condensador, fornecidas pelo fabricante. 


\begin{tabular}{|l|r|}
\hline Capacidade de refrigeração & $8,4 \mathrm{~kW}$ \\
\hline Superfície de troca de calor & $1,44 \mathrm{~m}^{2}$ \\
\hline $\mathrm{P}_{\text {casco }}$ & $24 \mathrm{~kg} / \mathrm{cm}^{2}$ \\
\hline $\mathrm{P}_{\text {tubo }}$ & $6 \mathrm{~kg} / \mathrm{cm}^{2}$ \\
\hline
\end{tabular}

Tabela 3.1 - Características nominais do condensador

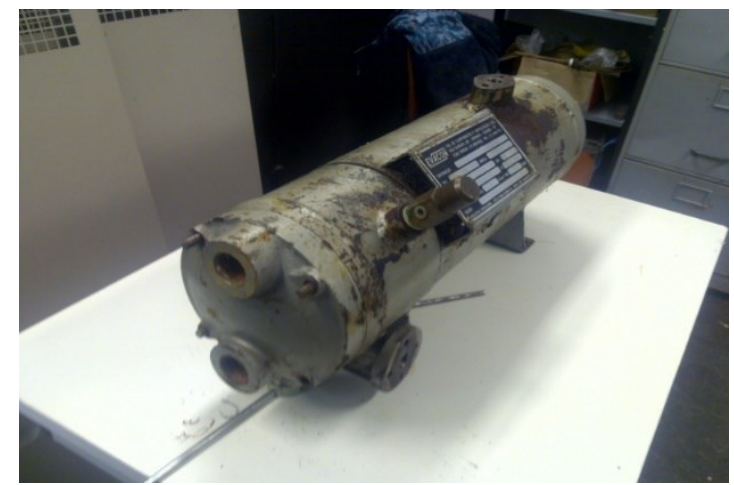

Figura 3.2 - Condensador fechado

O condensador possui um escoamento cruzado e contra-corrente, seu funcionamento consiste em seis passes de água no tubo e um passe de refrigerante no casco, como mostrado na Figura 3.3, Figura 3.4 e no esquema elucidado pela Figura 3.5.

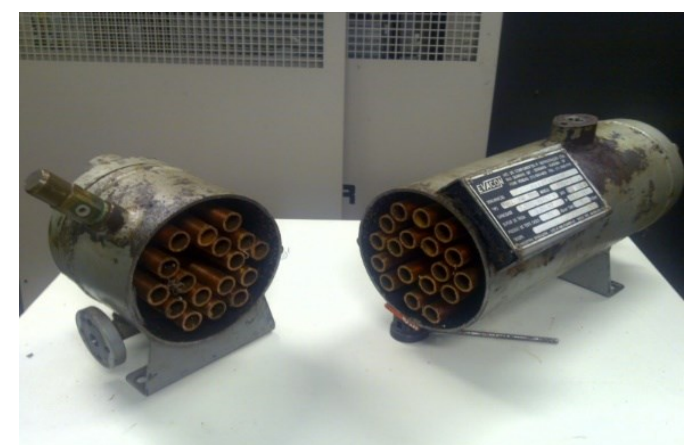

Figura 3.3 - Condensador aberto

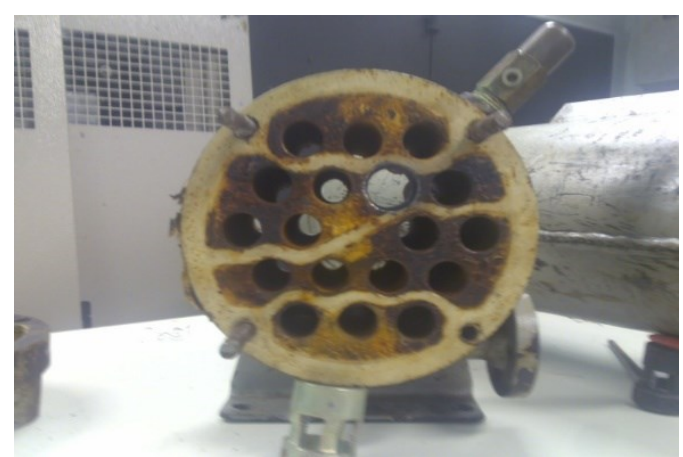

Figura 3.4 - Passes dos tubos no condensador

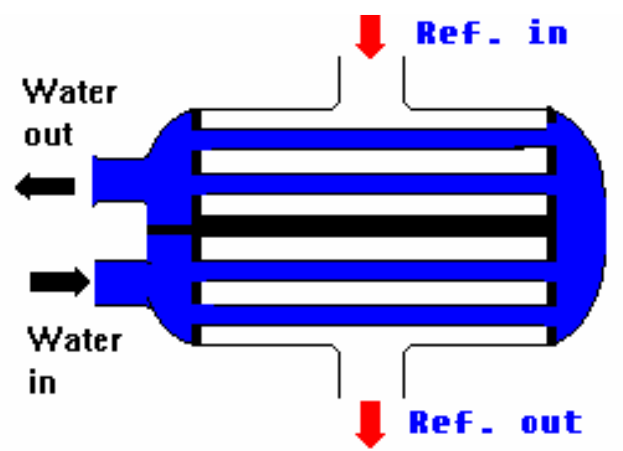

Figura 3.5 - Escoamento dos fluidos no condensador 
Para a utilização do modelo determinístico, se faz necessário conhecer os parâmetros geométricos do condensador em estudo, estes foram medidos e constam na seguinte tabela:

\begin{tabular}{|l|r|}
\hline \multicolumn{2}{|l|}{ Detalhes geométricos do condensador } \\
\hline Número de tubos & 18 \\
\hline Número de fileiras de tubo & 5 \\
\hline Comprimento do tubo & $0,445 \mathrm{~m}$ \\
\hline Comprimento do condensador & $0,530 \mathrm{~m}$ \\
\hline Diâmetro externo da carcaça & $0,150 \mathrm{~m}$ \\
\hline Diâmetro interno da carcaça & $0,144 \mathrm{~m}$ \\
\hline Espaçamento entre tubos (transv., diag. e long) & $0,028 \mathrm{~m}$ \\
\hline Detalhes geométricos do tubo & \\
\hline Diâmetro externo & $0,0189 \mathrm{~m}$ \\
\hline Diêmtro interno & $0,0167 \mathrm{~m}$ \\
\hline Diâmetro do tubo na raiz da aleta & $0,0176 \mathrm{~m}$ \\
\hline Passo das aletas & $0,000816 \mathrm{~m}$ \\
\hline Comprimento da parte sem aletas do tubo & $0,090 \mathrm{~m}$ \\
\hline Comprimento do tubo que não troca calor & $0,020 \mathrm{~m}$ \\
\hline
\end{tabular}

\section{Tabela 3.2 - Dados geométricos do condensador}

Vale ressaltar que uma grande área superficial do tubo é composta por microaletas de cobre rosqueadas (roscas de perfil quadrado) neste, enquanto que nos extremos não há presença de aletas, sendo os tubos totalmente lisos. Para a medição da maioria dos parâmetros referentes aos tubos foi utilizado um projetor de perfil localizado no Laboratório de Metrologia da PUC-Rio.

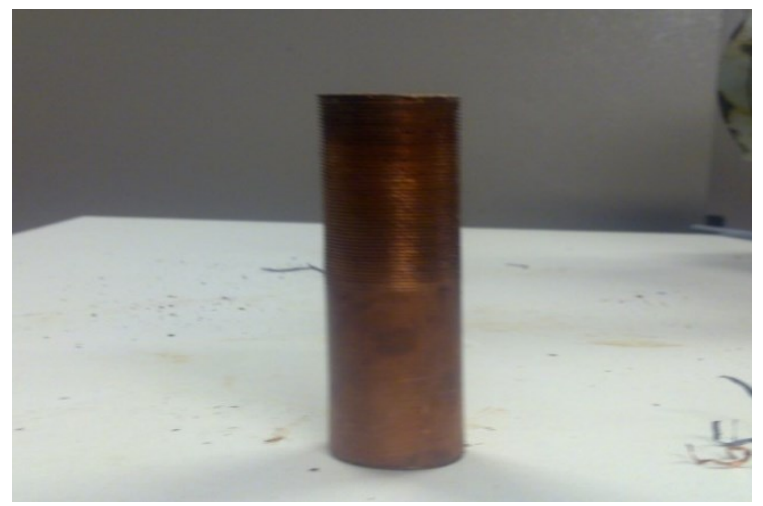

Figura 3.6 - Tubo aletado 
Para fins de análise, o condensador pode ser dividido em três zonas de transferência de calor (dessuperaquecimento, bifásica e subresfriamento), a mudança de temperatura para os dois fluidos ocorre da forma como está mostrado na Figura 3.7, onde a linha superior representa a temperatura do refrigerante e a linha inferior representa a temperatura da água.

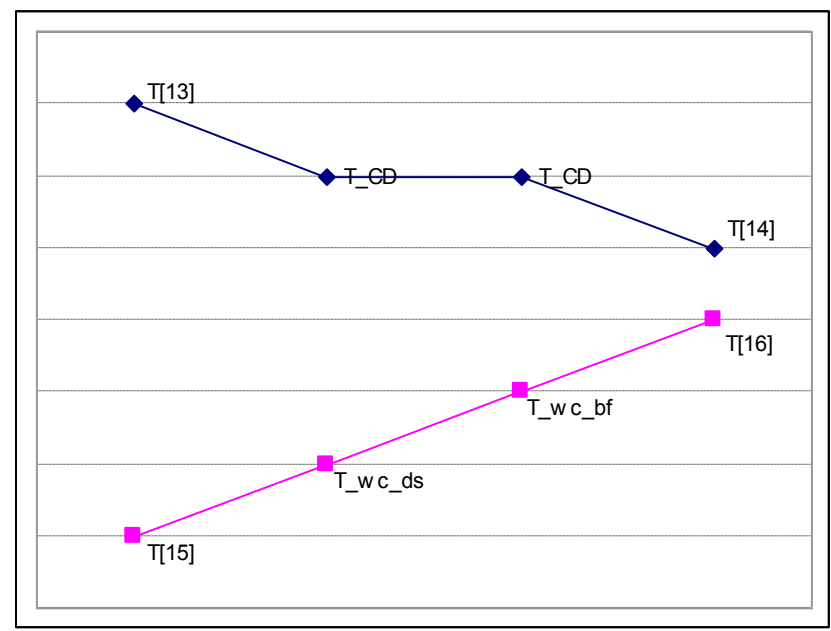

Figura 3.7 - Evolução das temperaturas dos fluidos ao longo do processo

Analisando o comportamento térmico do refrigerante, ficam claras as três zonas de troca de calor existentes no condensador. O dessuperaquecimento ocorre no primeiro trecho, no qual o fluido refrigerante passa da temperatura de entrada do condensador, $T_{13}$, para a temperatura de condensação, $T_{C D}$. A zona bifásica é observada no trecho de temperatura constante e igual à temperatura de condensação. A zona de sub-resfriamento é caracterizada pelo resfriamento do fluido da temperatura de condensação até a temperatura de saída do condensador, $T_{14}$.

\section{Modelagem Matemática}

A seguir, apresentaremos o modelo matemático utilizado, com todas as operações realizadas e relações termodinâmicas. A solução numérica e seu código computacional permitirão a análise comparativa com os dados medidos em laboratório e a respectiva validação do modelo desenvolvido. 


\subsection{Modelagem do Condensador}

Nesta seção serão descritas todas as equações e relações termodinâmicas utilizadas na simulação numérica do condensador apresentado anteriormente. $\mathrm{O}$ modelo desenvolvido no presente trabalho, assume que o condensador pode ser dividido em duas zonas distintas de troca de calor no lado do refrigerante: a zona de dessuperaquecimento mais bifásica e a zona de subresfriamento, conforme pode-se observar na Figura 4.1

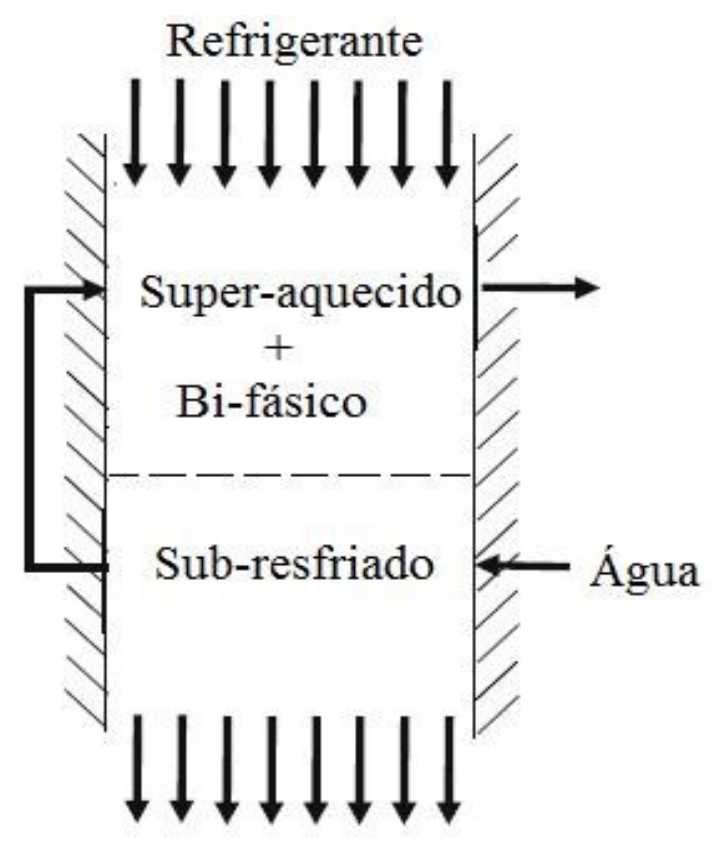

Figura 4.1 - Divisão de zonas do condensador

São adotadas também as hipóteses de regime permanente e volume de controle adiabático, ou seja, não há variações dos parâmetros com o tempo e perdas de calor para o meio externo. Para uma melhor compreensão do modelo matemático, este será subdividido em duas partes, uma para cada zona de troca de calor. 


\subsection{Zona de Dessuperaquecimento mais Bifásica}

\subsubsection{Cálculo das Áreas e Eficiência da Aleta}

Nesta seção serão explicitados os cálculos das áreas envolvidas na troca de calor da zona de dessuperaquecimento e bifásica, além do equacionamento detalhado dos parâmetros relacionados à eficiência das aletas. Alguns destes cálculos serão reutilizados na região de subresfriamento

Para algumas situações complexas de troca de calor que veremos mais adiante, foi utilizada uma simplificação das geometrias envolvidas afim de viabilizar uma melhor modelagem física de tais condições. Sendo assim, nesses casos a região geométrica de interesse se concentra nas áreas unitárias do tubo onde há troca de calor, tanto no lado do refrigerante quanto da água. O modelo da área unitária no lado do refrigerante leva em consideração a área superficial de uma única aleta somada a área superficial do tubo entre duas aletas, conforme a Figura 4.2. Seu equacionamento é da seguinte forma:

$$
A_{\text {un }, r}=A_{\text {un }, \text { fin }}+A_{\text {un }, p}
$$

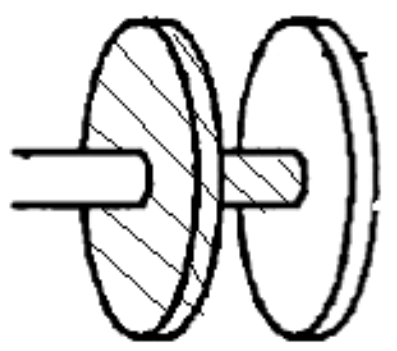

Figura 4.2 - Modelo da área unitária no lado do refrigerante

Onde, $A_{u n, f i n}$, área superficial de uma única aleta e $A_{u n, p}$, área superficial do tubo entre duas aletas têm as seguintes expressões:

$$
A_{\text {un }, \text { fin }}=2 \pi\left[\frac{d_{\text {ext }}^{2}-d_{\text {raiz }}^{2}}{4}\right]+\pi d_{\text {ext }} \delta_{\text {fin }}
$$




$$
A_{\text {un,p }}=\pi p_{\text {fin }} d_{\text {raiz }}
$$

Já para o lado da água, a área de troca de calor unitária que interessa é relacionada ao interior do tubo e tem a seguinte expressão:

$$
A_{\text {un }, a}=\pi d_{\text {raiz }}\left(\delta_{\text {fin }}+p_{\text {fin }}\right)
$$

Para o cálculo da área entre os tubos, por onde o fluido refrigerante escoa, foi adotada a seguinte geometria da Figura 4.3:

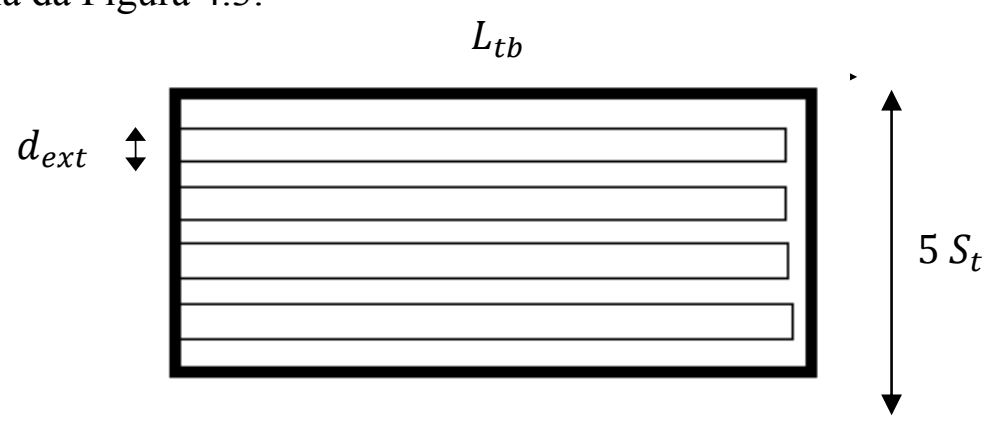

Figura 4.3 - Esquema da geometria da área entre os tubos

Através desse esquema, chega-se ao equacionamento da área:

$$
A_{b t w, t b}=L_{t b}\left(5 S_{t}-4 d_{\text {ext }}\right)
$$

A área interna do tubo, por onde a água escoa, é de fácil expressão:

$$
A_{\text {int }, t b}=\frac{\pi d_{i n t}^{2}}{4}
$$


Segundo Shah (1985), a eficiência de uma aleta circular depende de seus parâmetros geométricos e das condições de troca de calor ao seu redor, conforme a Figura 4.4 e as equações abaixo:

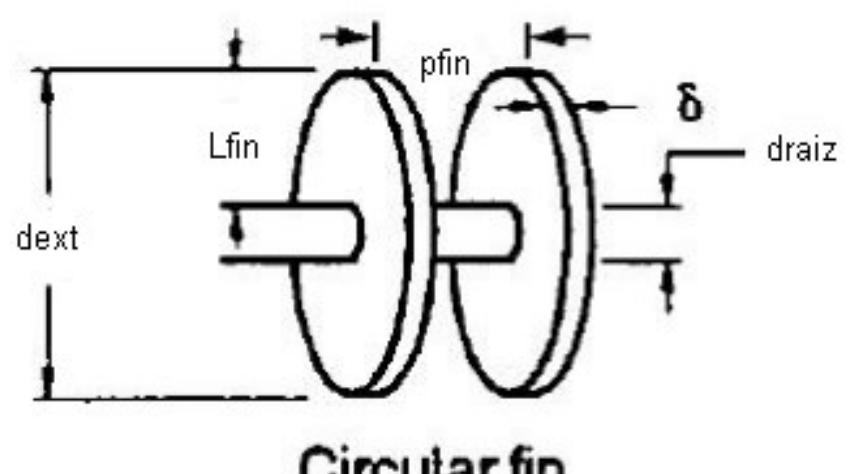

Figura 4.4 - Parâmetros geométricos de uma aleta circular

$$
\begin{gathered}
r_{d}=\frac{d_{\text {ext }}}{d_{\text {raiz }}} \\
a=r_{d}^{-0,246} \\
b=0,9107+0,0893 r_{d} \\
L_{e q}=L_{\text {fin }}+\frac{\delta_{\text {fin }}}{2} \\
m=\left[2 \frac{\propto_{r, N . f i n}}{\delta_{\text {fin }} k_{t b}}\right]^{1 / 2} \\
n=10^{\left(0,13 m L_{e q}-1,3863\right)}
\end{gathered}
$$




$$
\begin{gathered}
\theta=m L_{e q} r_{d}{ }^{n} \\
e=0,6+2,257 r_{d}^{-0,445}
\end{gathered}
$$

Se $\theta>e$, a eficiência da aleta circular fica da seguinte forma:

$$
\phi_{f i n}=a\left(m L_{e q}\right)^{-b}
$$

Caso contrário, temos:

$$
\phi_{\text {fin }}=\frac{\tanh (\theta)}{\theta}
$$

Com isso, chega-se ao equacionamento da área efetiva de uma aleta e de sua efetividade

$$
\begin{aligned}
& A_{e f}=A_{u n, f i n} \phi_{f i n}+A_{u n, p} \\
& \eta_{0}=1-\frac{A_{u n, f i n}}{A_{u n, p}}\left(1-\phi_{f i n}\right)
\end{aligned}
$$

A elaboração do modelo baseou-se na área interna total dos tubos, $A_{c d}$, ou seja, a área de troca de calor no lado da água. Foram estabelecidas também três outras correlações entre as áreas e números de fileiras de tubos da região de dessuperaquecimento mais bifásico e da região de subresfriamento. Todas as correlações são mostradas a seguir:

$$
A_{c d}=\pi d_{i n t} L_{t b} n_{t b}
$$




$$
\begin{gathered}
A_{c d}=A_{s r}+A_{d s b f} \\
\frac{n_{f i l, t b, t o t}}{A_{c d}}=\frac{n_{f i l, t b, d s b f}}{A_{d s b f}} \\
n_{f i l, t b, s r}=n_{f i l, t b, t o t}-n_{f i l, t b, d s b f}
\end{gathered}
$$

\subsubsection{Cálculo do Coeficiente Convectivo do Refrigerante}

Para o cálculo do coeficiente convectivo local do refrigerante, deve-se levar em conta a separação da superfície aletada e lisa dos tubos. O efeito da presença de aletas em aumentar a área superficial de troca de calor faz com que as correlações dessas duas regiões se baseiem em parâmetros termodinâmicos diferentes.

\subsubsection{Região Aletada}

Beatty and Katz (1948) propuseram a seguinte correlação para condensação no lado do refrigerante em um tubo horizontal aletado:

$$
\alpha_{r, f \text { in }}=0,689\left[\frac{\rho_{l}^{2} k_{l}^{3} g h_{l v}}{\mu_{l}\left(T_{s a t}-T_{p}\right) D_{e}}\right]^{1 / 4}
$$

Onde $D_{e}$ é o diâmetro equivalente, calculado pela seguinte expressão:

$$
\frac{1}{D_{e}{ }^{1 / 4}}=1,30 \frac{A_{\text {un }, \text { fin }} \theta}{A_{\text {ef }}\left[\pi\left(d_{\text {ext }}^{2}-d_{\text {raiz }}^{2}\right) / d_{\text {raiz }}\right]^{1 / 4}}+\frac{A_{\text {un }, p}}{A_{\text {ef }} d_{\text {ext }}^{1 / 4}}
$$


A equação (23) é válida somente para condensação ao redor de um único tubo. Na presença de tubos vizinhos, as condições termodinâmicas para condensação são significativamente diferentes, onde é necessário contabilizar a influência do cisalhamento do vapor superaquecido por entre as fileiras de tubos. A correlação para o cálculo do coeficiente convectivo local do refrigerante para $N$ fileiras escalonadas de tubos aletados [3], $n_{f i l, t b, d s b f}$, é da seguinte forma:

$$
\propto_{r, N . f i n}=\left[0,5 \propto_{c i s}^{2}+\left(0,25 \propto_{c i s}^{4}+\propto_{r}^{4}\right)^{1 / 2}\right]^{1 / 2} n_{f i l, t b, d s b f}-1 / 6
$$

na qual o termo de cisalhamento $\propto_{c i s}$ é dado pela equação abaixo:

$$
\propto_{c i s}=0,9\left[\frac{\rho_{l} V_{v} d_{e x t}}{\mu_{l}}\right]^{1 / 2}\left[\frac{k_{l}}{d_{\text {ext }}}\right]
$$

A velocidade do refrigerante no estado vapor superaquecido $V_{v}$ é calculada a partir de sua vazão mássica, conhecida em nossa simulação numérica:

$$
V_{v}=\frac{\dot{m_{r}}}{\rho_{v} A_{b t w, t b}}
$$

\subsubsection{Região sem Aleta}

$\mathrm{Na}$ região onde não há aletas, o coeficiente convectivo local do refrigerante para condensação ao redor de um único tubo horizontal pode ser calculado pela correlação de Dhir and Lienhard (1971):

$$
\alpha_{r}=0,729\left[\frac{\rho_{l} k_{l}^{3}\left(\rho_{l}-\rho_{v}\right) g h_{l v}}{\mu_{l}^{2}\left(T_{s a t}-T_{p}\right) d_{\text {ext }}}\right]^{1 / 4}
$$


De forma similar à região aletada, a presença de outros tubos na vizinhança requer um ajuste na equação (28) para $N$ fileiras escalonadas de tubos, segundo Incropera and DeWitt (2002):

$$
\propto_{r, N}=\propto_{r} n_{f i l, t b, d s b f}-1 / 4
$$

\subsubsection{Cálculo do Coeficiente Convectivo da Água}

A correlação de Dittus-Boelter (1930) para o Número de Nusselts em situações de convecção forçada dentro de tubos, é utilizada para o cálculo do coeficiente convectivo da água:

$$
N u_{a}=0,023 R e_{a}^{0,8} \operatorname{Pr}_{a}^{0,4}
$$

Onde $R e_{a}$ é o Número de Reynolds e $P r_{a}$ o Número de Prandtl do escoamento:

$$
\begin{gathered}
R e_{a}=\frac{\rho_{a} V_{a} d_{i n t}}{\mu_{a}} \\
P r_{a}=\frac{c p_{a} \mu_{a}}{k_{a}}
\end{gathered}
$$

A velocidade $V_{a}$ da água é calculada de forma similar a do refrigerante, através de sua vazão mássica conhecida:

$$
V_{a}=\frac{\dot{m_{a}}}{\rho_{a} A_{\iota n t, t b}}
$$


A correlação de Dittus-Boelter somente é aplicável quando não há mudança de fase do fluido escoando internamente no tubo e para as seguintes faixas de Número de Reynolds e Prandtl: $10.000<\operatorname{Re}<120.000$ e $0,7<\operatorname{Pr}<120$. Satisfeitas tais condições, chega-se ao equacionamento final do coeficiente convectivo da água:

$$
\alpha_{a}=\frac{k_{a}}{d_{\text {int }}} N u_{a}
$$

\subsubsection{Cálculo da Temperatura Média da Parede Externa do Tubo}

Para o cálculo da temperatura média da parede externa do tubo, o modelo da área unitária (explicitado anteriormente), tanto no lado do refrigerante quanto da água, foi utilizado.

A resistência térmica devido a condução de calor na parede do tubo deve ser considerada nessa modelagem, da seguinte forma:

$$
R_{k}=\frac{d_{r a i z}-d_{i n t}}{k_{t b}}
$$

Com isso chega-se ao cálculo do coeficiente global de troca de calor unitário no lado da água:

$$
U_{u n, a}=\frac{1}{\frac{1}{\alpha_{a}}+R_{k}}
$$

Através das equações de troca de calor unitária por convecção no lado do refrigerante e da água, cria-se um sistema de duas equações e duas variáveis que nos fornece o valor da temperatura média da parede externa do tubo:

$$
Q_{u n}^{\cdot}=\alpha_{r, f i n} \eta_{0} A_{u n, r}\left(T_{c d}-T_{p}\right)
$$




$$
\dot{Q}_{u n}=U_{u n, a} A_{u n, a}\left(T_{p}-T_{e, a_{d s b f}}\right)
$$

\subsubsection{Cálculo do Coeficiente Global de Troca de Calor e da Efetividade}

Com ambos os coeficientes locais (região lisa e aletada) calculados, através de analogia elétrica, considerando-os como resistências convectivas em paralelo, encontra-se o coeficiente convectivo equivalente da zona de dessuperaquecimento mais bifásica:

$$
\frac{1}{\alpha_{r, N, e q}}=\frac{\frac{1}{\eta_{0} \propto_{r, N . f i n}} \frac{1}{\alpha_{r, N}}}{\frac{1}{\eta_{0} \propto_{r, N . f i n}}+\frac{1}{\alpha_{r, N}}}
$$

Com todos os parâmetros necessários calculados, chega-se ao equacionamento do coeficiente global de troca de calor da zona de dessuperaquecimento mais bifásica:

$$
U_{d s b f}=\frac{1}{\frac{d_{\text {raiz }}}{d_{\text {int }} \alpha_{r, N, e q}}+\frac{d_{\text {raiz }} \ln \left(\frac{d_{\text {raiz }}}{d_{\text {int }}}\right)}{2 k_{t b}}+\frac{1}{\alpha_{a}}}
$$

A efetividade é obtida a partir da seguinte formulação:

$$
\epsilon=1-\exp \left(-U_{d s b f} \frac{A_{d s b f}}{\dot{m}_{a} c p_{a}}\right)
$$

\subsubsection{Cálculo do Calor Total trocado}

Nesta seção serão apresentados os balanços de energia no fluído refrigerante, na água e a equação de troca de calor entre eles, respectivamente. Estas são: 


$$
\begin{gathered}
\dot{Q}_{d s b f}=\dot{m}_{r}\left(h_{e, r, d s b f}-h_{s, r, d s b f}\right) \\
\dot{Q}_{d s b f}=\dot{m}_{a} c p_{a}\left(T_{s, a, d s b f}-T_{e, a, d s b f}\right) \\
\dot{Q}_{d s b f}=\dot{m}_{a} c p_{a} \epsilon\left(T_{r, c d, d s b f}-T_{e, a, d s b f}\right)
\end{gathered}
$$

\subsection{Zona de subresfriamento}

O cálculo para a região subresfriada é bastante semelhante a de dessuperquecimento mais bifásica. Desta vez, a principal diferença, é o fato de o fluido refrigerante estar em seu estado líquido, consequentemente, um novo coeficiente convectivo de troca de calor deverá ser calculado. Vale ressaltar que o cálculo do coeficiente convectivo da água não será calculado novamente, pois a diferença de temperatura desta não é significativamente grande para modificar suas propriedades termodinâmicas.

\subsubsection{Cálculo do Coeficiente Convectivo do Refrigerante}

\subsubsection{Região Aletada}

Para o cálculo do coeficiente convectivo do refrigerante no estado líquido fluindo sobre uma superfície circular aletada, faz-se uso da Correlação de Farrel [4] e Briggs \& Young [5], que é mostrada abaixo:

$$
\alpha_{r, f i n, s r}=0,0232 \operatorname{Re}_{r}^{0,8} \operatorname{Pr}_{r}^{\frac{1}{3}} \frac{k_{r, l s}}{d_{\text {ext }}}
$$

onde, tanto o valor de Reynolds quanto o de Prandtl será o já calculado para o coeficiente convectivo do fluido sobre uma região não aletada. 


\subsubsection{Região sem Aleta}

Para este cálculo, será feito o uso da correlação de Zukauskas (1987), que para $N$ fileiras escalonadas de tubos é dada por:

$$
\alpha_{r, N, s r}=k_{r, l s} \frac{N u_{r, N}}{d_{\text {ext }}}
$$

onde, Reynolds será representado por um novo valor, referente à esta região de subresfriamento, pois a velocidade muda bruscamente. Assim sendo:

$$
R e_{r}=\rho_{r, l s} V_{\max , r, s r} \frac{d_{\text {ext }}}{\mu_{r, l s}}
$$

sendo que, $V_{\max , r, s r}$ será:

$$
V_{\max , r, s r}=S_{t} \frac{V_{r, s r}}{S_{t}-d_{e x t}}
$$

se $S_{d}>\frac{S_{t}+d_{\text {ext }}}{2}$, do caso contrário,

$$
V_{\text {max }, r, s r}=S_{t} \frac{V_{r, s r}}{2\left(S_{t}-d_{\text {ext }}\right)}
$$

O número de Prandtl será dado pelo próprio programa através de função padrão para propriedades de fluidos, mediante definição de dois parâmetros físicos, pressão e temperatura. Contudo, para $N$ fileiras, com arranjo escalonado, segundo Zukauskas, se faz necessário, também, o cálculo de um novo número de Nusselt, que é:

$$
N u_{r, N}=F N u_{r}
$$


onde, $N u_{r}$ dependerá diretamente de Reynolds, como pode-se ver na tabela abaixo.

\begin{tabular}{|c|c|c|}
\hline Arranjo & Intervalo de $R e_{D}$ & Correlação \\
\hline \multirow[b]{4}{*}{ Em linha } & $0-100$ & $\mathrm{Nu}_{\mathrm{r}}=0,9 \mathrm{Re}_{\mathrm{r}}^{0,4} \operatorname{Pr}^{0,36}\left(\operatorname{Pr} / \operatorname{Pr}_{\mathrm{p}}\right)^{0,25}$ \\
\hline & $100-1000$ & $\mathrm{Nu}_{\mathrm{r}}=0,52 \operatorname{Re}_{\mathrm{r}}^{0,5} \operatorname{Pr}^{0,36}\left(\operatorname{Pr} / \operatorname{Pr}_{\mathrm{p}}\right)^{0,25}$ \\
\hline & $1000-2 \times 10^{5}$ & $\mathrm{Nu}_{\mathrm{r}}=0,27 \mathrm{Re}_{\mathrm{r}}^{0,63} \operatorname{Pr}^{0,36}\left(\operatorname{Pr} / \operatorname{Pr}_{\mathrm{p}}\right)^{0,25}$ \\
\hline & $2 \times 10^{5}-2 \times 10^{6}$ & $\mathrm{Nu}_{\mathrm{r}}=0,033 \operatorname{Re}_{\mathrm{r}}^{0,8} \operatorname{Pr}^{0,4}\left(\operatorname{Pr} / \operatorname{Pr}_{\mathrm{p}}\right)^{0,25}$ \\
\hline \multirow[b]{4}{*}{ Escalonado } & $0-500$ & $\mathrm{Nu}_{\mathrm{r}}=1,04 \mathrm{Re}_{\mathrm{r}}{ }^{0,4} \operatorname{Pr}^{0,36}\left(\operatorname{Pr} / \operatorname{Pr}_{\mathrm{p}}\right)^{0,25}$ \\
\hline & $500-1000$ & $\mathrm{Nu}_{\mathrm{r}}=0,71 \operatorname{Re}_{\mathrm{r}}^{0,5} \operatorname{Pr}^{0,36}\left(\operatorname{Pr} / \operatorname{Pr}_{\mathrm{p}}\right)^{0,25}$ \\
\hline & $1000-2 \times 10^{5}$ & $\mathrm{Nu}_{\mathrm{r}}=0,35\left(\mathrm{~S}_{\mathrm{t}} / \mathrm{S}_{\mathrm{L}}\right)^{0,2} \operatorname{Re}_{\mathrm{r}}^{0,6} \operatorname{Pr}^{0,36}\left(\operatorname{Pr} / \operatorname{Pr}_{\mathrm{p}}\right)^{0,25}$ \\
\hline & $2 \times 10^{5}-2 \times 10^{6}$ & $\mathrm{Nu}_{\mathrm{r}}=0,031\left(\mathrm{~S}_{\mathrm{t}} / \mathrm{S}_{\mathrm{L}}\right)^{0,2} \operatorname{Re}_{\mathrm{r}}{ }^{0,8} \operatorname{Pr}^{0,36}\left(\operatorname{Pr} / \operatorname{Pr}_{\mathrm{p}}\right)^{0,25}$ \\
\hline
\end{tabular}

Tabela 4.1 - Correlações para fluxo cruzado sobre tubos, para $\mathrm{N}>16$ e $0,7<\operatorname{Pr}<500$. $\left(\mathrm{P}_{\mathrm{p}}\right.$ é avaliado em $\left.\mathrm{T}_{\mathrm{p}}\right)$

$F$ é um fator de correção proposto por Zukauskas (1987) a ser multiplicado por $N u_{r}$ quando o número de fileiras de tubos for inferior a 16 e Reynolds superior a 1000. Este intervalo de valores de F é evidenciado na Tabela 4.2.

\begin{tabular}{|l|c|c|c|c|c|c|c|c|}
\hline \multicolumn{1}{|c|}{$\mathbf{N}_{\mathbf{L}}$} & $\mathbf{1}$ & $\mathbf{2}$ & $\mathbf{3}$ & $\mathbf{4}$ & $\mathbf{5}$ & $\mathbf{7}$ & $\mathbf{1 0}$ & $\mathbf{1 3}$ \\
\hline Em linha & 0,70 & 0,80 & 0,86 & 0,90 & 0,93 & 0,96 & 0,98 & 0,99 \\
\hline Escalonado & 0,64 & 0,76 & 0,84 & 0,89 & 0,93 & 0,96 & 0,98 & 0,99 \\
\hline
\end{tabular}

Tabela 4.2 - Fator de correção proposto por Zukauskas (1987)

\subsubsection{Cálculo do Coeficiente Global de Troca de Calor da Zona Subresfriada}

Novamente se fará necessária, assim como para a região de dessuperaquecimento mais bifásico, ser feita a analogia elétrica, considerando esses dois coeficientes convectivos como resistências em paralelo. Sendo assim, é obtida a seguinte formulação:

$$
\frac{1}{\alpha_{r, N, e q, s r}}=\frac{\frac{1}{\eta_{0} \propto_{r, f i n, s r}} \frac{1}{\propto_{r, N, s r}}}{\frac{1}{\eta_{0} \propto_{r, f i n, s r}}+\frac{1}{\propto_{r, N, s r}}}
$$

Para que $\alpha_{r, N, e q}$ seja obtido, se faz necessário, também, o cálculo de um novo valor para a eficiencia da aleta, porém, não são todos os parâmetros deste cálculo que irão mudar, apenas o 
valor de $m$, e assim, consequentemente, $n$ e $\theta$ também irão ter seus valores diferentes dos calculados para a região de dessuperaquecimento mais bifásico. Feito isso, já pode ser calculada o coeficiente global de troca de calor:

$$
U_{s r}=\frac{1}{\frac{d_{\text {raiz }}}{d_{\text {int }} \alpha_{r, N, e q, s r}}+\frac{d_{\text {raiz }} \ln \left(\frac{d_{\text {raiz }}}{d_{\text {int }}}\right)}{2 k_{t b}}+\frac{1}{\alpha_{a}}}
$$

\subsubsection{Cálculo do Calor Total trocado}

As mesmas correlações utilizadas no tópico 4.2.6 deste capítulo, serão utilizadas para a ocasião atual, ficando as formulações da seguinte forma:

$$
\begin{gathered}
\dot{Q_{s r}}=\dot{m}_{a} c p_{a}\left(T_{s, a, s r}-T_{s, a, d s b f}\right) \\
\dot{Q_{s r}}=\dot{m}_{r}\left(h_{s, r, d s b f}-h_{s, r, s r}\right) \\
\dot{Q_{s r}}=\dot{m}_{r} c p_{r} \epsilon_{s r}\left(T_{r, c d, d s b f}-T_{s, a, d s b f}\right)
\end{gathered}
$$

onde,

$$
\epsilon_{s r}=\frac{2}{1+C+\left(1+C^{2}\right)^{0,5}\left[\frac{1+\exp \left(-N T U_{s r}\left(1+C^{2}\right)^{0,5}\right.}{1-\exp \left(-N T U_{s r}\left(1+C^{2}\right)^{0,5}\right.}\right]}
$$

A partir do cálculo da efetividade, obtêm-se o NTU, assim torna-se possível o cálculo da área utilizada para o subresfriamento do refrigerante:

$$
N T U=\frac{A_{s r} U_{s r}}{C_{\min }}
$$

onde, 


$$
C=\frac{C_{\min }}{C_{\max }}
$$

e

$$
\begin{gathered}
C_{r, s r}=\dot{m}_{r} c p_{r} \\
C_{a, s r}=\dot{m}_{a} c p_{a}
\end{gathered}
$$

\subsection{Calor Total Trocado pelo Condensador}

Após todos estes cálculos, obtêm-se o calor total trocado no condensador, que consiste na simples soma do calor trocado na zona de dessuperaquecimento mais bifásica com o calor trocado na zona de subresfriamento do fluido, logo:

$$
\dot{Q}_{\text {cond }}=\dot{Q}_{s r}+\dot{Q}_{d s b f}
$$

\subsection{Queda de Pressão no Condensador}

Segundo Campos (2009), devido à conclusão de Xuan e Li (2003), as correlações para o fator de atrito considerando fluxo monofásico no escoamento, podem ser estendidas aos modelos para nanofluidos. No trabalho citado acima é possível também concluir que a queda de pressão dos nanofluidos pode ser modelada pela equação de Darcy-Weisbach, como segue abaixo:

$$
\Delta P_{n f}=\frac{G_{n f}^{2} f_{n f} L_{t u b o}}{2 \rho_{n f} D_{h, n f}}
$$

O fator $G_{n f}$ é o proporcional a velocidade na equação Darcy-Weisbach simplificada, e pode ser calculado da seguinte forma:

$$
G_{n f}=\frac{\dot{m}_{n f}}{A_{\text {transv }}}
$$


Para números de Reynolds intermediários, o fator de atrito pode ser determinado pela equação abaixo Haaland, (1983):

$$
\frac{1}{\sqrt{f_{n f}}}=-1,8 \log _{10}\left(\left(\frac{6,9}{R e_{n f}}\right)+\left(\frac{r_{t u b o}}{3,7}\right)^{1,11}\right)
$$

O número de Reynolds é calculado como segue abaixo:

$$
R e_{n f}=\frac{\rho_{n f} V_{n f} D_{h, n f}}{\mu_{n f}}
$$

\subsection{Modelagem do Nanofluido}

\subsubsection{Cálculo da Densidade dos Nanofluidos}

Segundo Rea et al., (2009), e derivado da regra das misturas, a densidade de um nanofluido pode ser definida por:

$$
\rho_{n f}=\emptyset_{n p} \rho_{n p}+\rho_{b f}\left(1-\emptyset_{n p}\right)
$$

\subsubsection{Cálculo da Viscosidade dos Nanofluidos}

Para a modelagem da viscosidade dos nanofluidos, foram consultados os seguintes trabalhos. No trabalho de Velagapudi et al., (2008), podem ser encontradas correlações apresentadas por Pak e Cho (1998) para a modelagem da viscosidade dinâmica dos nanofluidos Óxidos de Alumínio+Água e Dióxido de Titânio+Água. Para os nanofluidos compostos por Cobre+Água, a correlação pode ser encontrada no trabalho de Chen et al., (2007). As correlações seguem abaixo:

Óxido Alumínio+Água

$$
\mu_{n f}=\mu_{b f}\left(1+39,118 \emptyset_{n p}+533,9 \emptyset_{n p}^{2}\right)
$$

Dióxido Titânio+Água

$$
\mu_{n f}=\mu_{b f}\left(1+5,45 \emptyset_{n p}+108,2 \emptyset_{n p}^{2}\right)
$$


Cobre+Água

$$
\mu_{n f}=\mu_{b f}\left(0,995+3,645 \emptyset_{n p}+468,72 \emptyset_{n p}^{2}\right)
$$

\subsubsection{Cálculo do Calor Específico dos Nanofluidos}

Segundo Rea et al., (2009), o calor específico de um nanofluido é obtido levando em consideração que o fluido base e as nanopartículas estão em equilíbrio térmico. O valor é obtido a partir de um balanço térmico entre o fluido e a partícula, e pode ser definido pela equação que segue.

$$
C_{p, n f}=\frac{\left(\emptyset_{n p} \rho_{n p} C_{p, n p}\right)+\left(\rho_{b f} C_{p, b f}\left(1-\emptyset_{n p}\right)\right)}{\rho_{n f}}
$$

\subsubsection{Cálculo da Condutividade Térmica dos Nanofluidos}

Segundo Boungiomo et al., (2009), Maxwell (1881) desenvolveu um modelo capaz de estimar a condutividade térmica para soluções contendo partículas esféricas e bem distribuídas em meio aquoso. Campos, (2009), cita que Maxwell foi um dos primeiros a estudar a condutividade térmica de soluções com estas características. E que em seu modelo, podem ser observadas duas principais considerações para o cálculo da condutividade térmica. Primeiro é possível considerar um sistema heterogêneo (fluido + partícula) com uma condutividade térmica efetiva $\mathrm{k}_{\mathrm{nf}}$, segundo é possível considerar que a temperatura da mistura é produzida pela condutividade de cada nanopartícula, $\mathrm{k}_{\mathrm{np}}$. De acordo com a abordagem citada, a equação encontrada é a seguinte:

$$
k_{n f}=\frac{k_{b f}\left(k_{n p}+2 k_{b f}+2 \emptyset_{n p}\left(k_{n p}-k_{b f}\right)\right)}{k_{n p}+2 k_{b f}-\emptyset_{n p}\left(k_{n p}-k_{b f}\right)}
$$




\subsubsection{Cálculo do Número de Prandtl dos Nanofluidos}

Para o cálculo do número de Prandtl, foi usada a correlação abaixo:

$$
\operatorname{Pr}_{n f}=\frac{C_{p, n f} \mu_{n f}}{k_{n f}}
$$

\section{Código Computacional e Solução Numérica}

\subsection{O Programa Utilizado (EES)}

Para a solução numérica do projeto, foi utilizado o programa $E E S^{\circledR}$ (Engeneering Equation Solver), desenvolvido pela F-Chart Software. O EES é um programa que pode resolver numericamente inúmeras equações algébricas não lineares associadas. Este é capaz, também, de solucionar equações integrais e diferenciais, fazer otimizações, fornecer análises de incerteza, realizar regressões lineares e não lineares, dentre muitas outras características. Um ponto importante do programa é a alta precisão termodinâmica e base de dados de propriedades que é fornecida para centenas de substâncias de uma maneira que permite ser usada na resolução de equações.

\subsection{Dados de Entrada}

O modelo terá como entrada de dados as seguintes variáveis exibidas na ordem de utilização do programa:

- Fluido refrigerante.

- Especificações do condensador, todas estas já foram explicitadas no capítulo.

- Entalpia de entrada do refrigerante no condensador.

- Temperatura de entrada da água no condensador.

- Vazão mássica da água. 
- Vazão mássica do refrigerante.

- Pressão do fluido refrigerante.

- Tipo de nanofluido;

- Fração volumétrica de nanopartículas;

\subsection{Código Computacional}

Todo o modelo foi resolvido em um único programa, porém, este, em seu corpo, encontrase dividido entre as regiões nas quais separamos nosso problema, ou seja, formulações destinadas à solução da região de dessuperaquecimento mais bifásica e à região de sub-resfriamento. Abaixo, código utilizado.

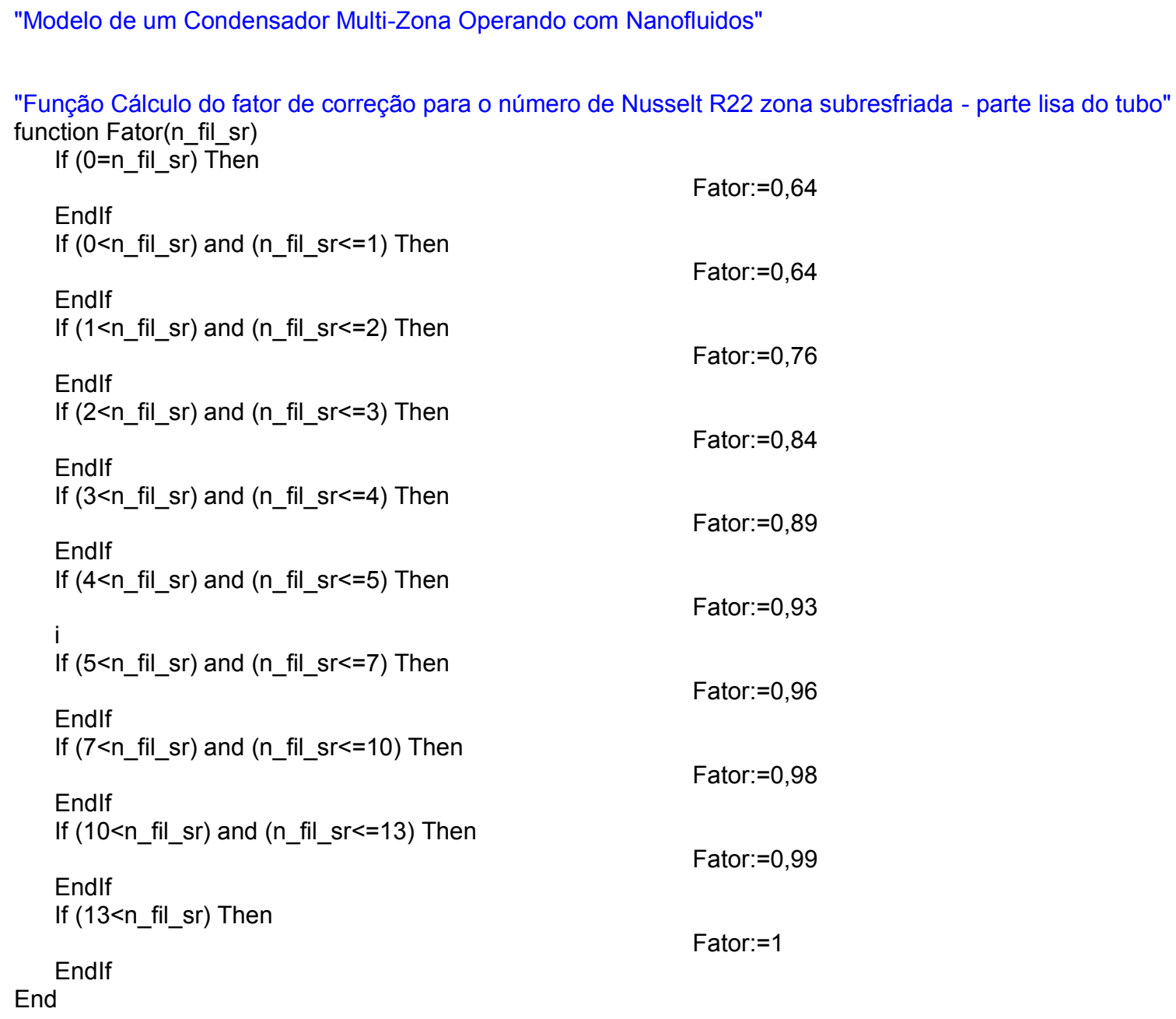




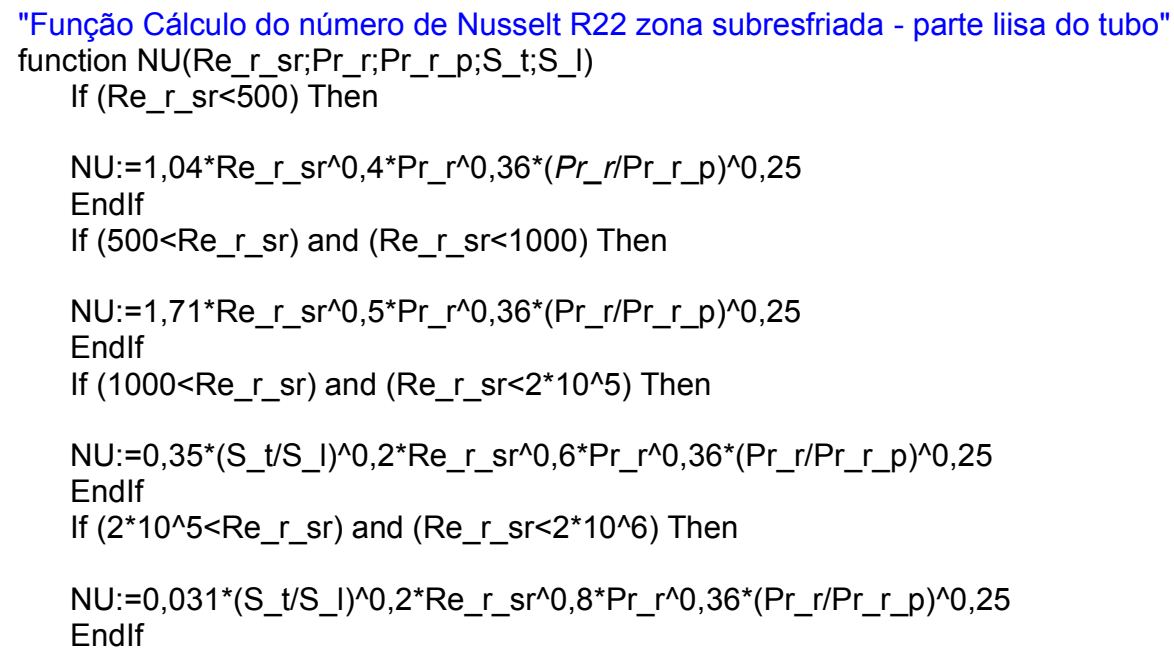

End

"Função cálculo velocidade refrigerante região subrefriada" function VEL(S_t;S_d;v;d_ext_tb)

If $\left(S \_d>\left(S \_t+d \_\right.\right.$ext_tb $\left.) / 2\right)$ Then

Else

Endlf

$$
\begin{aligned}
& V E L:=S \_t^{*} v /\left(S \_t-d \_e x t \_t b\right) \\
& V E L:=S \_t^{*} v /\left(2^{*}\left(S \_t-d \_e x t t b\right)\right)
\end{aligned}
$$

End

"Função Eficiência da Aleta"

function FIN(theta;e;a;m;I_eq;b)

If (theta>e) Then

Else

$\mathrm{FIN}:=a^{*}\left(\mathrm{~m}^{*} \mid \mathrm{eq}\right)^{\wedge}(-\mathrm{b})$

Endlf

FIN:=tanh(theta)/theta

End

PROCEDURE NanoFluidProp (phi_np;D_np;T_nf;P_nf:c_p_nf;rho_nf;mu_nf;k_nf;Pr_nf;k_np;rho_np)

"Determines Water-based nanofluid Thermophysical Properties"

F_k=Convert(W/m-K; kW/m-

$\mathrm{K})$

"Base fluid: water"

"converts from $\mathrm{W}$ to $\mathrm{kW"}$

IF $(T$ nf < 0) THEN

T_nf $=0,5$

"to avoid out of range error messages with intermediate calculations; works for water"

c_p_bf=SPECHEAT(Water; $\left.T=T \_n f ; P=P \_n f\right)$

"base fluid specific heat"

rho_bf=DENSITY(Water;T=T_nf;P=P_nf)

"base fluid density"

mu_bf=VISCOSITY(Water;T=T_nf;P=P_nf)

"base fluid viscosity"

k_bf=F_k*CONDUCTIVITY(Water;T=T_nf;P=P_nf)

"base fluid thermal conductivity"

Pr_bf=PRANDTL(Water;T=T_nf;P=P_nf)

"Prandtl number of the base fluid"

"Nanofluid" 
$\{$ "Alumina - Water nanofluid"

$\mathrm{Nf} \$=' \mathrm{Al} 2 \mathrm{O} 3-\mathrm{H} 2 \mathrm{O}$

"nanoparticle properties"

C_p_np $=0,880$

"Alumina nanoparticle specific heat - Rea et al., 2009"

rho_np $=3920$

"Alumina nanoparticle bulk density - Rea et al., 2009"

k_np=0,035

"Allumina nanoparticle thermal conductivity - Buongiorno et al., 2009"

"viscosity"

mu_nf $=m u \_b f^{*}\left(1+39,118^{*}\right.$ phi_np+533,9*phi_np^2)

"Al2O3-H2O nanofluid viscosity -Buongiorno, 2006"\}

$\{$ "Titania - Water nanofluid"

$\mathrm{Nf} \$=$ 'TiO2-H2O'

"nanoparticle properties"

c_p_np $=0,686$

" Titania nanoparticle specific heat - Velagapudi et al., 2008"

rho_np $=4250$

"Titania nanoparticle bulk density - Velagapudi et al., 2008"

k $n p=0,008938$

"Titania nanoparticle thermal conductivity - Velagapudi et al., 2008"

"viscosity"

mu_nf=mu_bf* $\left(1+5,45^{*}\right.$ phi_np+108,2*(phi_np^2))

"Titania-H2O nanofluid viscosity -Buongiorno, 2006"\}

$\{\quad$ "Copper - Water nanofluid"

$\mathrm{Nf} \$=' \mathrm{Cu}-\mathrm{H} 2 \mathrm{O}$

"nanoparticle properties"

c $\mathrm{p} n \mathrm{np}=0,385$

" Copper nanoparticle specific heat - Velagapudi et al., 2008"

rho_np $=8933$

"Copper nanoparticle bulk density - Velagapudi et al., 2008"

k_np $=0,400$

"Copper nanoparticle thermal conductivity - Velagapudi et al., 2008"

"viscosity" 2008"\}

mu_nf=mu_bf* $\left(0,995+3,645^{*}\right.$ phi_np+468,72*(phi_np^2)) "Cu-H2O nanofluid viscosity -Velagapudi et al.

"Copper Oxide - Water nanofluid"

$\mathrm{Nf} \$={ }^{\prime} \mathrm{CuO}-\mathrm{H} 2 \mathrm{O}$

Tnf $\mathrm{x}=\mathrm{T} \mathrm{nf}+273,15$

"nañoparticle properties"

c_p_np $=0,385$

"Copper nanoparticle specific heat - Velagapudi et al., 2008"

rho_np $=8933$

"Copper nanoparticle bulk density - Velagapudi et al., 2008"

k_np $=0,400$

"Copper nanoparticle thermal conductivity - Velagapudi et al., 2008"

"viscosity"

mu_nf $=(1 / 1000)^{\star} \exp \left(\left(\left(20587^{*} \text { phi_np^2)+(15857*phi_np }\right)+1078,3\right)^{\star}(1 /\right.$ Tnf_x $\left.)\right)-((-$

$107,12^{\star}$ phi_np^2)+(53,548*phi_np)+2,8715)) "Cu-H2O nanofluid viscosity [Pa.s] - Kulkarni et al., 2006"

"nanofluid properties - general correlations - é a media ponderada entrea a densidade dea particula e a densidade do fluido, considero uma mistura dos dois e tiro a media"

rho_nf=phi_np*rho_np+((1-

phi_np) $)^{\star}$ rho_bf)

"nanofluid density - Rea et al., 2009"

c_p_nf $=\left(\left(\right.\right.$ phi_np*rho_np* ${ }^{*}$ _p_np $\left.)+\left(\left(1-p h i \_n p\right)^{*} r h o \_b f^{*} c \_p \_b f\right)\right) / r h o \_n f$

"é um balanço de energia"

$\mathrm{L} 11=1 / 3$

"parameter for nanofluid thermal conductivity - Nan et. al, 1997" 
L_33=1/3

"parameter for nanofluid thermal conductivity - Nan et. al, 1997"

) $R \_d b=10^{\wedge}(-$

resistance, Buongiorno et al., 2009"

"Kaptiza interfacial (particle-fluid) thermal

a_11=D_np

"particle diameter"

gamma $=\left(3^{*} R \_d b * k \_b f\right) /\left(\left(a \_11 / 2\right)\right)$

"parameter for nanofluid thermal conductivity - Nan et. al, 1997"

$\mathrm{k} \mid \mathrm{c} \_11=\mathrm{k} \_n \mathrm{p} /\left(1+\left(\right.\right.$ gamma* $\left.\left.\mathrm{L} \_11^{*}\left(\mathrm{k} \_n p / \mathrm{k} \_b f\right)\right)\right)$

"parameter for nanofluid thermal conductivity - Nan et. al, 1997"

$\mathrm{k} \mid \mathrm{c} \_33=\mathrm{k} \_n \mathrm{p} /\left(1+\left(\mathrm{gamma}{ }^{*} \mathrm{~L} \_33^{*}\left(\mathrm{k} \_n p / k \_b f\right)\right)\right)$

"parameter for nanofluid thermal conductivity - Nan et. al, 1997"

k_bf)) beta_11=(k|c_11-k_bf $) /\left(k \_b f+L \_11^{*}\left(k \mid c \_11\right.\right.$

"parameter for nanofluid thermal conductivity - Nan et. al, 1997"

beta_33 $=\left(k \mid c \_33-k \_b f\right) /\left(k \_b f+L \_33^{*}\left(k \mid c \_11-\right.\right.$

k_bf))

"parameter for nanofluid thermal conductivity - Nan et. al, 1997"

k_nf_maxwell=k_bf* $\left(k \_n p+2^{*} k \_b f+2^{*} p h i \_n p^{*}\left(k \_n p-k \_b f\right)\right) /\left(k \_n p+\left(2^{*} k \_b f\right)-p h i \_n p^{*}\left(k \_n p-\right.\right.$ k_bf))

Büongiorno et. al, 2009"

"nanofluid thermal conductivity - Maxwell,

$\mathrm{k} \_n f=k \_n f \_m a x w e l l$

$\overline{P r} \_n f=\left(\mathrm{c} \_\bar{p} \_n f^{*} m u \_n f\right) / k \_n f$

"nanofluid Prandtl number"

END

CALL NanoFluidProp (0;0,000000001;25;100:c_p_nf;rho_nf;mu_nf;k_nf;Pr_nf;k_np;rho_np)

"Queda de Pressão Lado da Água - Tube Side"

P_ag $=100$

rho=rho_nf

$\mathrm{mi}=\mathrm{mu}$. $\mathrm{nf}$

rugo $=0,0000015$

"tubo de

cobre $=0,0015 \mathrm{~mm} "$

$v 1=m \_d o t \_a /\left(\right.$ rho*A_tb_int $\left.{ }^{*} 3\right)$

$\mathrm{v} 2=\mathrm{m} \_$dot_a/(rho*A-tb_int $\left.{ }^{*} 6\right)$

$\operatorname{Re} 1=($ rho * $v 1$ *d_raiz_tb) $/ \mathrm{mi}$

$\operatorname{Re} 2=($ rho * v2 *d raiz tb $) / \mathrm{mi}$

"Equação de Colebrook simplificada -> Haaland 1983 - considera Reinolds e rugosidade"

fat1=1 / ((-1,8* $\left(\right.$ LOG10 $\left.\left.\left.\left((6,9 / \operatorname{Re} 1)+\left((\text { rugo/3,7 })^{\wedge} 1,11\right)\right)\right)\right)^{\wedge} 2\right)$

fat2 $=1 /\left(\left(-1,8^{\star}\left(\operatorname{LOG} 10\left((6,9 / \operatorname{Re} 2)+\left((\text { rugo/3,7 })^{\wedge} 1,11\right)\right)\right)\right)^{\wedge} 2\right)$

$\mathrm{L}=0,445$

$\mathrm{di}=\mathrm{d}$ raiz tb $/ 2$

Atv $=\overline{3}, 14^{\bar{*}}(($ d_raiz_tb^2)/4)

$\mathrm{G} 1=\mathrm{m}$ dot_a/( $\left.3^{*} \mathrm{Atv}\right)$

$\mathrm{G} 2=m \_$dot_a $a /\left(6^{*} \mathrm{Atv}\right)$

DELTAP1 $=$ fat $1{ }^{*}\left(\left(3^{*} \mathrm{~L}\right) / \mathrm{di}\right) *\left(\left(\mathrm{G} 1^{\wedge} 2\right) /\left(2^{*} \mathrm{rho}\right)\right)$ *

$(1 / 1000)$

"Dividindo por mil para sair em $\mathrm{kPa}$

DELTAP2 $=$ fat2 ${ }^{*}\left(\left(6^{*} \mathrm{~L}\right) / \mathrm{di}\right) *\left(\left(\mathrm{G} 2^{\wedge} 2\right) /\left(2^{*} \mathrm{rho}\right)\right)$ *

$(1 / 1000)$

"Dividindo por mil para sair em kPa"

DELTAP_tot $=2{ }^{*}$ DeltaP1 $+2{ }^{*}$ DeltaP2

"Vazões mássicas constantes" 
"Declaração do fluido refrigerante a ser utilizado"

"m_dot_r=0,0233

"Vazão mássica do refrigerante"

"m_dot_a=18,5/60

$[\mathrm{kg} / \mathrm{s}]^{\prime \prime}$

"Vāão mássica da água"

$[\mathrm{kg} / \mathrm{s}]^{\prime \prime}$

$g=g \#$

"Gravidade"

"Zona de Desuperaquecimento + Bifásico"

"T_r_e_sabf =

100,2

"2"

$T$ r_cd_sabf =

T_SAT(R22;P=P_r_s_sabf)

"Temperatura de condensação do R-22"

"P_e = 203,34

$P \bar{r}$ s sabf

$=P \_e^{\bar{*}} 6,894757$

"Pressão de condensação do R-22"

"T_a_e_sr =

26,7

"Temperatura da água na entrada da zona super aquecida + bifásica"

"[C]"

[Psi]"

"[kPa]"

h_r_e_sabf =

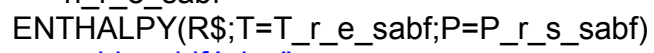

"Temperatura do R-22 na entrada da zona super

aquecida + bifásica"

"Dados geométricos do condensador"

$\mathrm{S} \mathrm{t}=$

0,028

"Passo transversal entre tubos"

"[m]"

$$
\text { S_I = }
$$

0,028

"Passo longitudinal entre tubos"

"[m]"

S_d =

0,028

"[m]"

"Passo diagonal entre tubos"

$\mathrm{n}$ tb $=18$

"[-

]" "Número de tubos"

n_fil_tb_tot $=5$

"Número de fileiras total de tubos"

n_fil_tb_sr $=$ MAX ( (n_fil_tb_tot $-\mathrm{n}$ _fil_tb_sabf $) ; 0)$

n_fil_tb_tot/A_cd =

n_fil_tb_sabf/A_sabf

"Relação de fileiras e áreas"

d ext_tb =

0,0189

"Diâmetro externo do tubo"

"[m]"

d_int_tb =

0,0167

"Diâmetro interno do tubo"

d_raiz_tb =

$0,01 \overline{76}$

"Diâmetro na raíz do tubo"

$\mathrm{L}$ tb $=$

0,445

"Comprimento do tubo"

delta fin =

0,000408

"Espessura aleta"

L_fin = d_ext_tb-

d_raiz_tb

"Comprimento da aleta"

"[m]"

"[m]"

"[m]"

"[m]"

"[m]" 
p_fin $=$
0,000408
"Passo da aleta"
A_tb_int=(pi*d_int_tb^2)/4 "[m]"
"Área interna do tubo por onde a água escoa"
A_p_r $=L$ _tb* $\left(5^{\star} S \_t-\right.$
4d_ext_tb)
"Área entre tubos para cálculo da velocidade do refrigerante"
A_cd=pi*d_int_tb*L_tb*n_tb

"Área interna total do Condensador"

A_ef $=$

A_fin_un*phi_fin+A_p_un

"Área efetiva"

A fin un $=\left(2^{*} \mathrm{pi}^{*}\left(\mathrm{~d}_{\text {e ext }} \mathrm{tb}^{\wedge} 2\right.\right.$ -

d_raiz_tb^2) $) /\left(4+\right.$ pi $^{*}$ d_ext_tb*delta fin $)$

A_p_un $=$ pi ${ }^{*}$ __fin ${ }^{*} d \_$raiz_tb

"Área superficial do tubo entre aletas"

A_un_r = A_fin_un+A_p_un $\quad$ "[m²]"

"Área unitária lado refrigerante - Área de uma aleta + Área passo"

A_un_a =

$\mathrm{pi}^{*}$ d_raiz_tb*(delta_fin $+\mathrm{p} \_$fin $)$

"Área unitária lādo dá água - Interior tubo"

eta $0=1-\left((\text { A fin_un/A_p_un })^{*}\left(1-p h i \_f i n\right)\right)$

"[m²]"

"Efetividade da área aletada unitária"

eta_0_sr = 1 - ((A_fin_un/A_p_un $\left.)^{*}\left(1-p h i \_f i n \_s r\right)\right) \quad$ "[-

]" "Efetividade da área aletada unitária na zona subresfriada"

"Propriedades - R-22, Água, Cobre"

h_lv $=\left(E N T H A L P Y\left(R \$ ; x=1 ; P=P \_r \_s \_s a b f\right)\right)-$

(ENTHALPY(R $\$ ; x=0 ; P=P$ r_s_sabf))

"Diferença de entalpia entre vapor e líquido"

T_p)

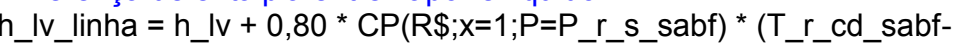

"Diferença de entalpia entre vapor e líquido com calor latente"

h $r$ s sabf $=$

ENTHĀLYY(R $\left.\$ ; x=0 ; P=P \_r \_s \_s a b f\right)$

aquecida"

k_r_Is = CONDUCTIVITY $(R \$ ; x=0 ; P=P \text { r_s_sabf })^{*} 0,001$

$\mathrm{K}]$ " "Condutividade térmica do R22 líquido saturado"

rho_r_ls =

DENSITY(R $\left.\$ ; x=0 ; P=P \_r \_s \_s a b f\right)$

mu $r$ ls $=$

VISCOSITY $\left(R \$ ; x=0 ; P=P \_r \_s \_s a b f\right)$

"[kPa*s]"

rho_r_sabf =

DENSITY(R $\$$;T=T_r_e_sabf;P=P_r_s_sabf)

"Densidade R22 vapor superaquecido"

rho_r_vs =

DENSITY(R $\left.\$ ; x=1 ; P=P \_r \_s \_s a b f\right)$

v r sabf $=$

m_dot_r/(rho_r_sabf*A_p_r)

"[m/s]"

$c p \_r=C P\left(R \$ ; x=0 ; P=P \_r \_s \_s a b f\right)$

"[kJ//kg*K]"

mu_a=mu_nf

"[kPa*s]"
"Entalpia do R-22 na saída da zona super

"[kW/m-

"[m^2]" "Área de uma aleta" "[m²]"

"[-

"[-

"[kJ/kg]" "[kJ/kg]" 


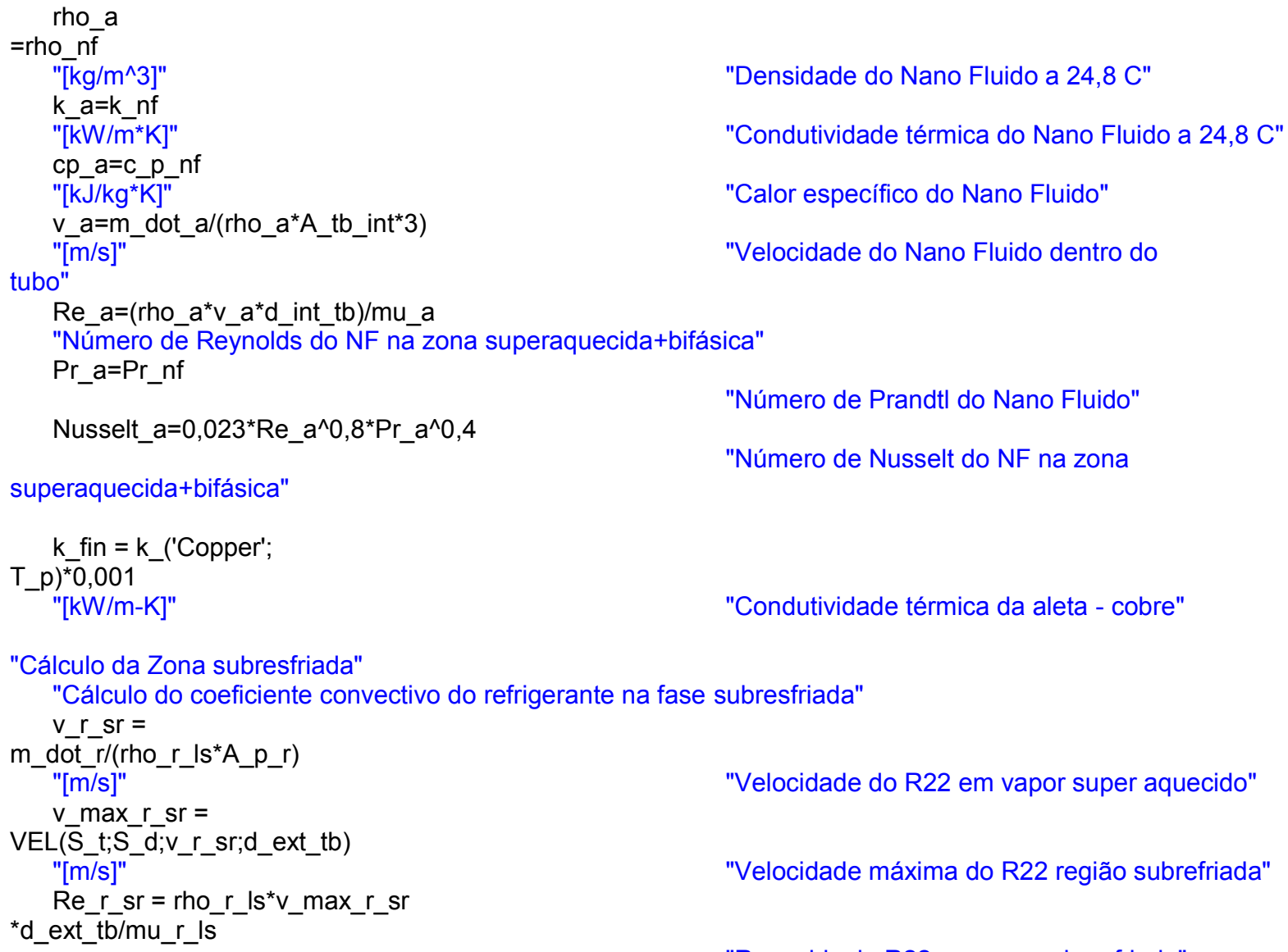

"Densidade do Nano Fluido a 24,8 C"

"Condutividade térmica do Nano Fluido a 24,8 C"

"Calor específico do Nano Fluido"

"Velocidade do Nano Fluido dentro do

"Cálculo da Zona subresfriada"

"Cálculo do coeficiente convectivo do refrigerante na fase subresfriada"

v_r_sr =

m_dot_rr $/($ rho_r_ls*A_p_r)

"[m/s]"

"Velocidade do R22 em vapor super aquecido"

$v \max r s r=$

VEL(S_t;S_d;v_r_sr;d_ext_tb)

"[m/s]"

Re_r_sr = rho_r_ls*v_max $r$ sr

*d_ext_tb/mu_r_ls

"Número de Prandtl do Nano Fluido"

"Número de Nusselt do NF na zona

"Condutividade térmica da aleta - cobre"

"Cálculo do coeficiente convectivo refrigerante superfície sem aleta - alpha - Correlação de Zukauskas (1987) - para um tubo apenas"

Pr_r = PRANDTL $\left(R 22 ; x=0 ; P=P \_r \_s \_s a b f\right)$

Pr_r_p = PRANDTL(R22;T=T_p;P=P_r_s sabf)

Nusselt_r $=N U\left(R e \_r \_s r ; P r \_r ; P r \_r \_p ; S \_t ; \bar{S} \_l\right)$

"Cálculo do coeficiente convectivo refrigerante superfície sem aleta - alpha - Correlação de Zukauskas (1987) - para N fileiras de tubos"

$\mathrm{F}=$ Fator(n_fil_tb_sr)

Nusselt_r $\bar{N}=F^{*}$ Nusselt $r$

alpha_r_N_sr $=\left(k \_r\right.$ I $s^{*}$ Nusselt_r_N $) / d \_$dext_tb Young"

"Cálculo do coeficiente convectivo refrigerante superfície com aleta - alpha - Correlação de Farrel / Briggs and alpha_r_fin_sr $=0,0232{ }^{*} \operatorname{Re} \_r \_s r^{\wedge} 0,8{ }^{*} \operatorname{Pr}_{-} r^{\wedge}(1 / 3)$ * k_r_ls/d_ext_tb

"Cálculo da eficiencia da aleta circular - phi - na zona subresfriada"

m_sr $=\left(\left(2^{*} \text { alpha_r_fin_sr } /(\text { delta_fin*k_fin })\right)\right)^{\wedge} 0,5$

$\mathrm{n} \_\mathrm{sr}=10^{\wedge}\left(0,13^{*} \mathrm{~m} \_\mathrm{sr}{ }^{*} \mathrm{I}\right.$ eq $\left.-1, \overline{3} 863\right)$

theta_sr $=m$ m_sr*I_eq ${ }^{*} r \_d^{\wedge} n \_s r$

phi fin $\mathrm{sr}=$

FIN(theta_sr;e;a;m_sr;I_eq;b)

"Fazendo analogia elétrica para as resistências - O coeficiente convectivo para os tubos aletados e tubos lisos, são considerados resistencias em paralelo - SUBRESFRIADO" 
1/alpha_r_eq_sr =

$(1 /($ eta_0_sr*alpha_r_fin_sr)*1/(alpha_r_N_sr))/(1/(eta_0_sr*alpha_r_fin_sr)+1/(alpha_r_N_sr))

$"\left[\mathrm{~kW} / \mathrm{m}^{\wedge} 2^{*} \mathrm{~K}\right] "$

"Cálculo do U - Coeficente Global - zona subresfriada"

U_sr $=1 /\left(\left(\right.\right.$ d_raiz_tb/(alpha_r_eq_sr ${ }^{*}$ d_int_tb $)+($ d_raiz_tb* $\ln ($ d_raiz_tb/d_int_tb $\left.\left.)) /\left(2^{*} k \_f i n\right)+1 /\left(a l p h a \_a\right)\right)\right)$

"[kW/K]" "Condutância Global"

"Cálculo do calor total trocado na área subresfriada"

Q_dot_sr $=\left(\text { m_dot_a* } c p \_a\right)^{*}\left(T \_a \_e \_s a b f-\right.$

T_a_e_sr)

Q_dot sr $=m$ m dot $r^{*}\left(h \_r\right.$ s_sabf-h_r_s_sr)

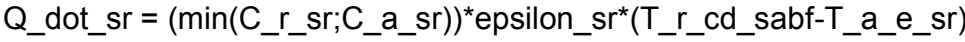

NTU_sr=(A_sr*U_sr) $/ \mathrm{min}\left(\mathrm{C} \_\mathrm{r}\right.$ sr $;$ C_a_sr)

$\mathrm{C}=\min \left(C_{-}\right.$r_sr;C_a_sr) $/ \max \left(\mathrm{C}_{-}\right.$r_sr; C_a_sr)

C_r_sr=m_dot_r* ${ }^{*}$ _r $r$

C a sr=m dot $a^{*} \mathrm{cp}^{-}$a

epsilon_sr ${ }^{\bar{*}}\left(1+\overline{\mathrm{C}}+\left(1+\bar{C}^{\wedge} 2\right)^{\wedge} 0,5\right)^{*}\left(1+\exp \left(-N T U \_\mathrm{sr}^{*}\left(1+\mathrm{C}^{\wedge} 2\right)^{\wedge} 0,5\right)\right)=2^{*}\left(1-\exp \left(-N T U \_\mathrm{sr}^{*}\left(1+\mathrm{C}^{\wedge} 2\right)^{\wedge} 0,5\right)\right)$

Q_dot_cd $=$ Q_dot_sr+Q_dot_sabf

"Calor total trocado do condensador"

"[kW]"

h_r_s_sr=ENTHALPY $(R \$ ; T=T$ __s_sr; $=0$ )

"Zona Superaquecida + Bifásica"

"Cálculo do coeficiente convectivo refrigerante superfície aleta - alpha - Correlação de BEATTY AND KATZ para um tubo apenas"

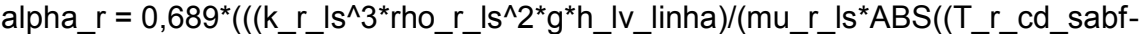

T_p) $\left.)))^{\wedge} 0, \overline{2} 5\right)^{\star} X$

"Cálculo de (1/diâmetro equivalente $)^{\wedge}(1 / 4)=$ X"

$X=1,3^{*}\left(\left(\left(A \_f i n \_u n^{*} p h i \_f i n\right) /\left(A \_e f^{*}\left(p^{*}\left(d \_e x t+t b^{\wedge} 2-\right.\right.\right.\right.\right.$

d_raiz_tb^2)/d_ext_tb $\left.\left.\left.)^{\wedge} 0,25\right)\right)\right)+A$ -

"[1/m]"

$X=\left(1 / D \_e\right)^{\wedge} 0,25$

"Cálculo do coeficiente convectivo refrigerante alpha superfície aletada- Correlação de BEATTY AND KATZ para N fileiras de tubos" 1/6) alpha_r_N $=\left(0,5^{*} \text { alpha_cis }{ }^{\wedge} 2+\left(0,25^{*} \text { alpha_cis }{ }^{\wedge} 4+\text { alpha_r }{ }^{\wedge} 4\right)^{\wedge} 0,5\right)^{\wedge} 0,5^{*} n \_f i l$ tb_sabf ${ }^{\wedge}(-$

alpha_cis $=$

$0,9^{*}\left(\left(\left(\text { rho_r_Is }{ }^{*} v \text { r_sabf }{ }^{*} \text { d_ext_tb }\right) / m u \_r \text { Is }\right)^{\wedge} 0,5\right)^{*}(\mathrm{k}$ _r_Is/d_ext_tb $)$

"[kW/mn' $\left.{ }^{*} \mathrm{~K}\right] "$

"Cálculo da eficiencia da aleta circular - phi"

$r$ d =

d_ext_tb/d_raiz_tb

I eq $=$

$L_{-}$fin+(delta_fin/2)

"Comprimento equivalente da aleta"

$\mathrm{m}=\left(\left(2^{*} \text { alpha_r_N } /\left(\text { delta_fin* }{ }^{*} \_ \text {fin }\right)\right)\right)^{\wedge} 0,5$

$\mathrm{n}=10^{\wedge}\left(0,13^{\star} \bar{m}^{\star} \mid\right.$ eq $\left.-1,3863\right)$

$a=r+d^{\wedge}(-0,246)$

$b=0,9107+\left(0,0893^{\star} r d\right)$

theta $=m^{*}$ I_eq ${ }^{*}\left(r_{-} d^{\wedge} n\right)$

$e=0,6+2,257^{*}\left(\left(r \_d\right)^{\wedge}(-0,445)\right)$

phi fin =

"Razão de diâmetros"

FIN(theta;e;a;m;I_eq;b) 


\section{"Eficiência da aleta"}

"Cálculo do coeficiente convectivo refrigerante alpha superfície lisa do tubo - Correlação de Dhir and Lienhard (1971) - Para um tubo"

alpha_r_I $=\left(0,729{ }^{*}\left(k \_r\right.\right.$ Is^3*rho_r_ls*(rho_r_ls-rho_r_vs $\left.){ }^{*} g^{*} h \_l v \_l i n h a\right) /\left(\left(m u \_r \_l s^{\wedge} 2\right) *\right.$

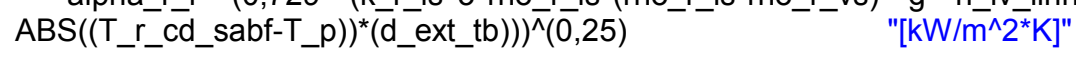

"Cálculo do coeficiente convectivo refrigerante alpha superfície lisa do tubo - Correlação de incropera and De Witt - Para N fileiras de tubo"

alpha_r_I_N = alpha_r_I* (n_fil_tb_sabf^(-1/4)) $\quad\left[\mathrm{kW} / \mathrm{m}^{\wedge} 2^{*} \mathrm{~K}\right] "$

"Cálculo do coeficiente convectivo alpha da água - Correlação de DITTUS-BOELTER - Convecção forçada dentro de tubos"

alpha_a $=\left(k \_a / d \_i n t \_t b\right)^{*}$ Nusselt_a $\quad\left[\left[\mathrm{kW} / \mathrm{m}^{\wedge} 2^{*} \mathrm{~K}\right] "\right.$

"Cálculo da Temperatura média da parede do tubo no lado do refrigerante"

$R \_k=\left(d \_r a i z \_t b-\right.$

d_int_tb) $/\left(k \_\right.$fin $)$

$"\left[\mathrm{~m}^{\wedge} 2 * \bar{K} / \mathrm{kW}\right] "$

"Resistência térmica devido a condução"

U_un_a =

1/(1/alphāa+R_k)

"[kW/ $\left.\mathrm{m}^{\wedge} 2^{*} \mathrm{~K}\right] " \quad$ "Coeficiente Global médio unitário de transferencia de calor Lado da água" T_p)

Q_dot_un = alpha_r*eta_0*A_un_r* ${ }^{*}\left(T \_r\right.$ cd _sabf-

"[kW]"

Q_dot_un $=$ U_un_a*A_un_a* $a^{*}(T-p-$

"Calor médio trocado unitário"

T_a_e_sabf)

"[kW]"

"Calor médio trocado unitário"

"Cálculo do U"

"Fazendo analogia elétrica para as resistências - O coeficiente convectivo para os tubos aletados e tubos lisos, são considerados resistencias em paralelo"

1/alpha_r_eq $=(1 /($ eta_0*alpha_r_N $) * 1 /($ alpha_r_I_N $)) /(1 /($ eta_0*alpha_r_N $)+1 /($ alpha_r_I_N $)$

) $\quad\left[\mathrm{kW} / \mathrm{m}^{\wedge}{ }^{\star} \mathrm{K}\right] "$

"Análogia de resistencia equivalente"

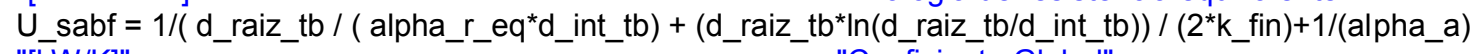

) "[kW/K]"

"Coeficiente Global"

"Cálculo do calor total trocado na área de superaquecimento + bifásico - Método da efetividade"

Q_dot_sabf $=$ m_dot_r $\left(h \_r \_e \_s a b f-\right.$

h_r_s_sabf)

"[kW]"

bifásica"

Q_dot_sabf $=(\text { m_dot_a*cp_a })^{*}\left(T \_a \_s \_s a b f-T \_a \_e \_s a b f\right) \quad$ "[kW]" "Deste equacionamento sai a

Temperatura da água na saída do superaquecido + bifásico"

Q_dot_sabf $=\left(\text { m_dot_a* }{ }^{*} c p \_a\right)^{*} \operatorname{epsilon}^{*}\left(T \_r \_c d \_s a b f-\right.$

T_a_e_sabf)

"Deste equacionamento sai a efetividade Epsilon"

"[kW]"

A_sr=MAX( (A_cd-

A_sabf_star);0)

"[mn 2$] "$

"Área da zona subresfriada"

epsilon $=1-(\exp (-$

U_sabf*A_sabf $/($ m_dot_a*cp_a $))$

"[-]" "Deste equacionamento sai a Área de troca superaquecido + bifásico"

A_sabf_star=MIN(A_cd;A_sabf)

DELTAT_sr = T_r_cd_sabf-T_r_s_sr

"Fim do Programa" 


\section{Resultados}

\subsection{Validação Modelo x Experimental}

Para a obtenção dos gráficos comparativos, fez-se o uso dos dados experimentais de Pruzaesky (2005). Foram utilizadas 30 corridas para as diferentes variáveis de entrada, ou seja, 30 testes diferentes. A tabela com os dados de entrada inseridos e as variáveis de saída calculadas é mostrada abaixo.

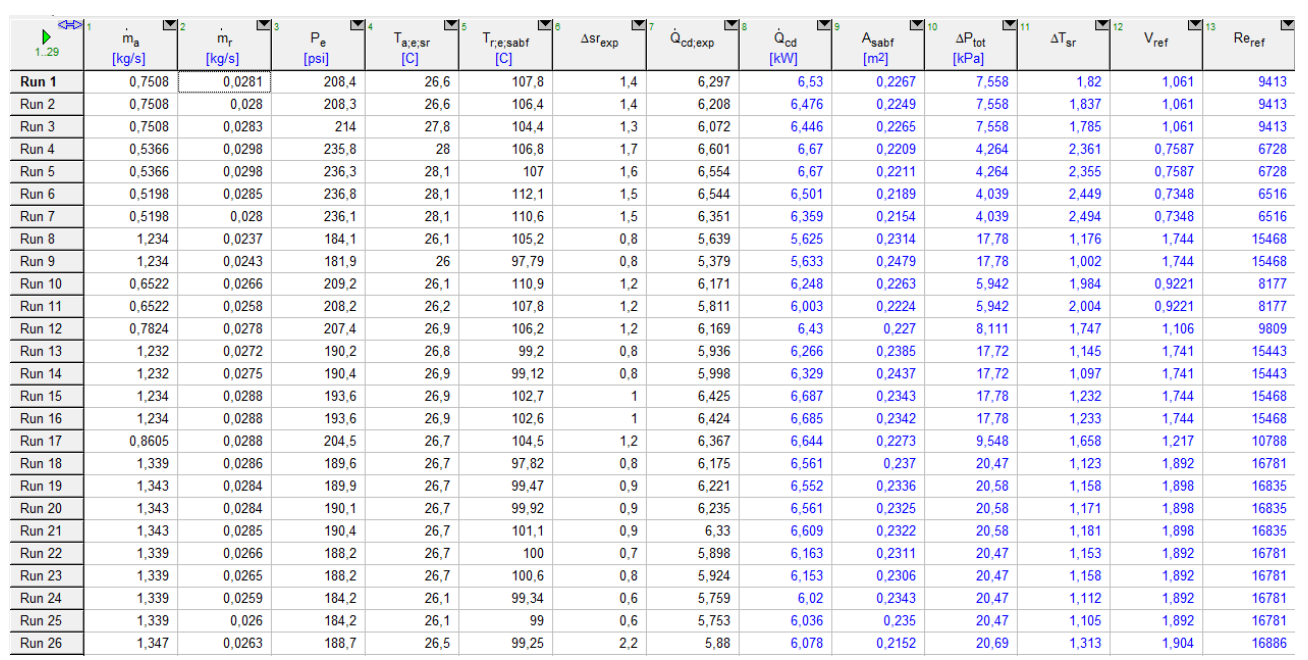

Tabela 6.1 - Tabela Paramétrica com dados de entrada e saída

onde, $\dot{m}_{a}, \dot{m}_{r} P_{e}, T_{a, e ; s r}, T_{r ; e, s a b f,}, \Delta s r_{\exp }$ e $Q c d_{\exp }$ são os dados de entrada.

Com isso, foi possível obter gráfico abaixo:

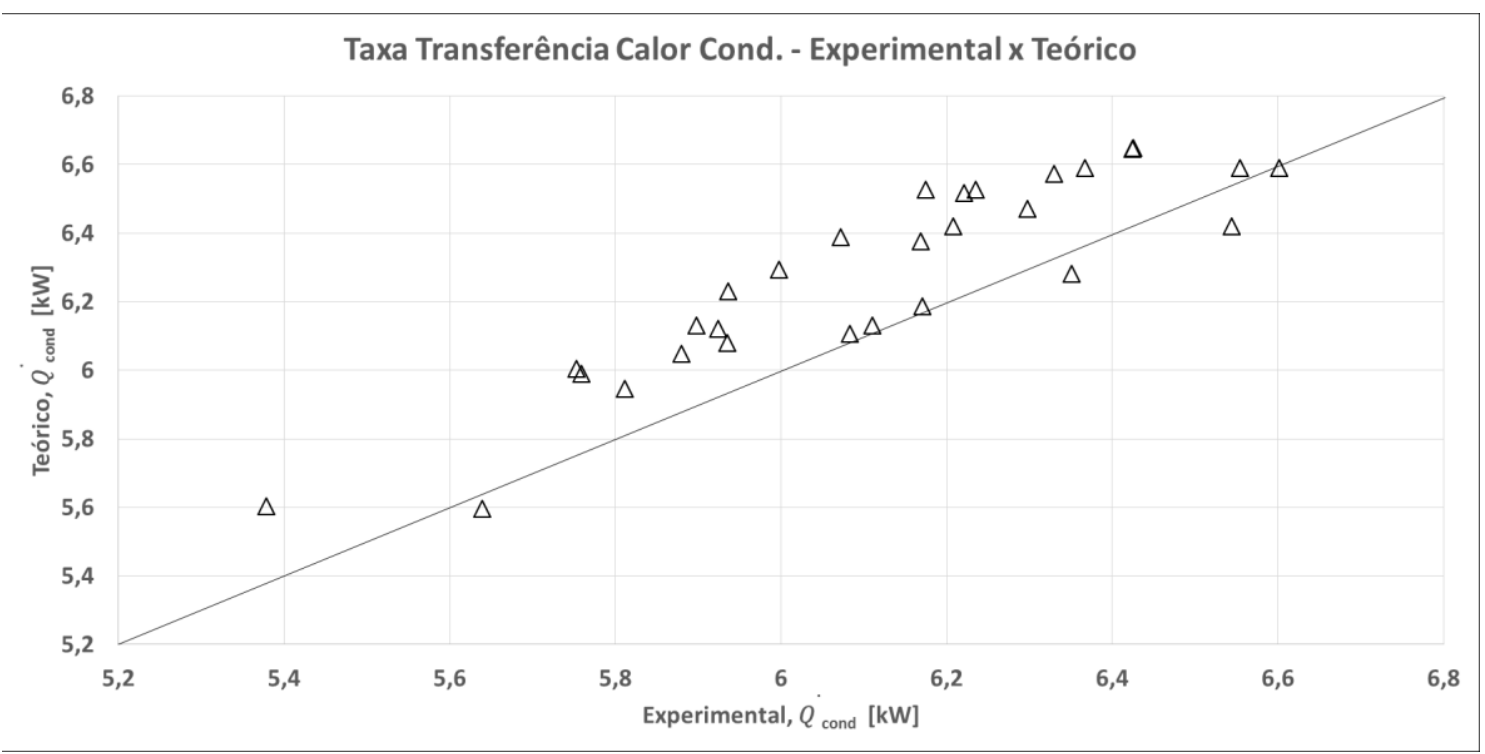

Figura 6.1 - Gráfico comparativo da taxa de calor trocada no condensador 


\subsection{Análise Paramétrica Nanofluidos}

\subsubsection{Propriedades Termofísicas dos Nanofluidos}

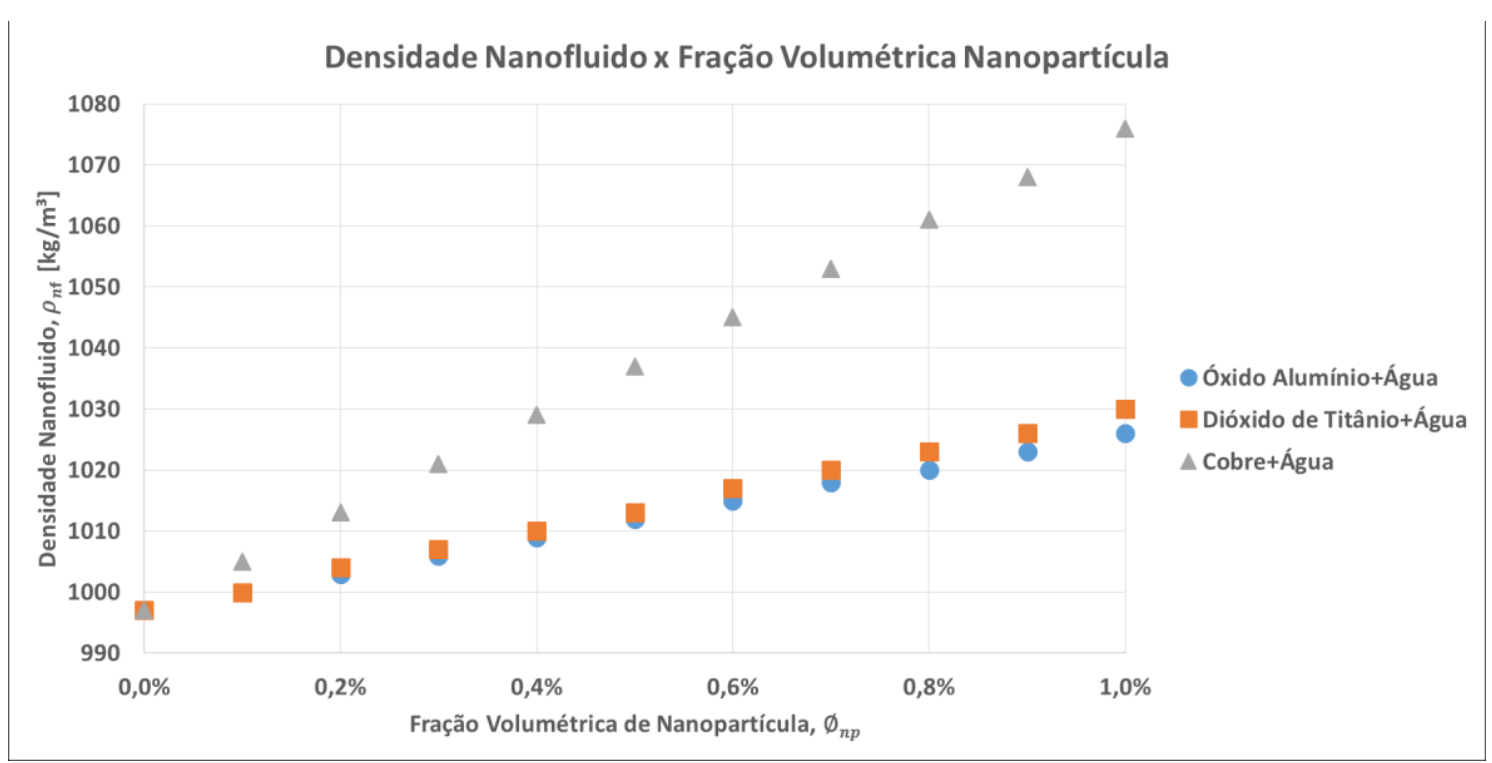

Figura 6.1 - Gráfico de Resultado: Densidade dos Nanofluidos

Como esperado, observa-se leve acréscimo na densidade das misturas com adição das nanopartículas. Mais expressivo no caso do cobre devido a maior densidade do elemento, cerca de 9 vezes a da água.

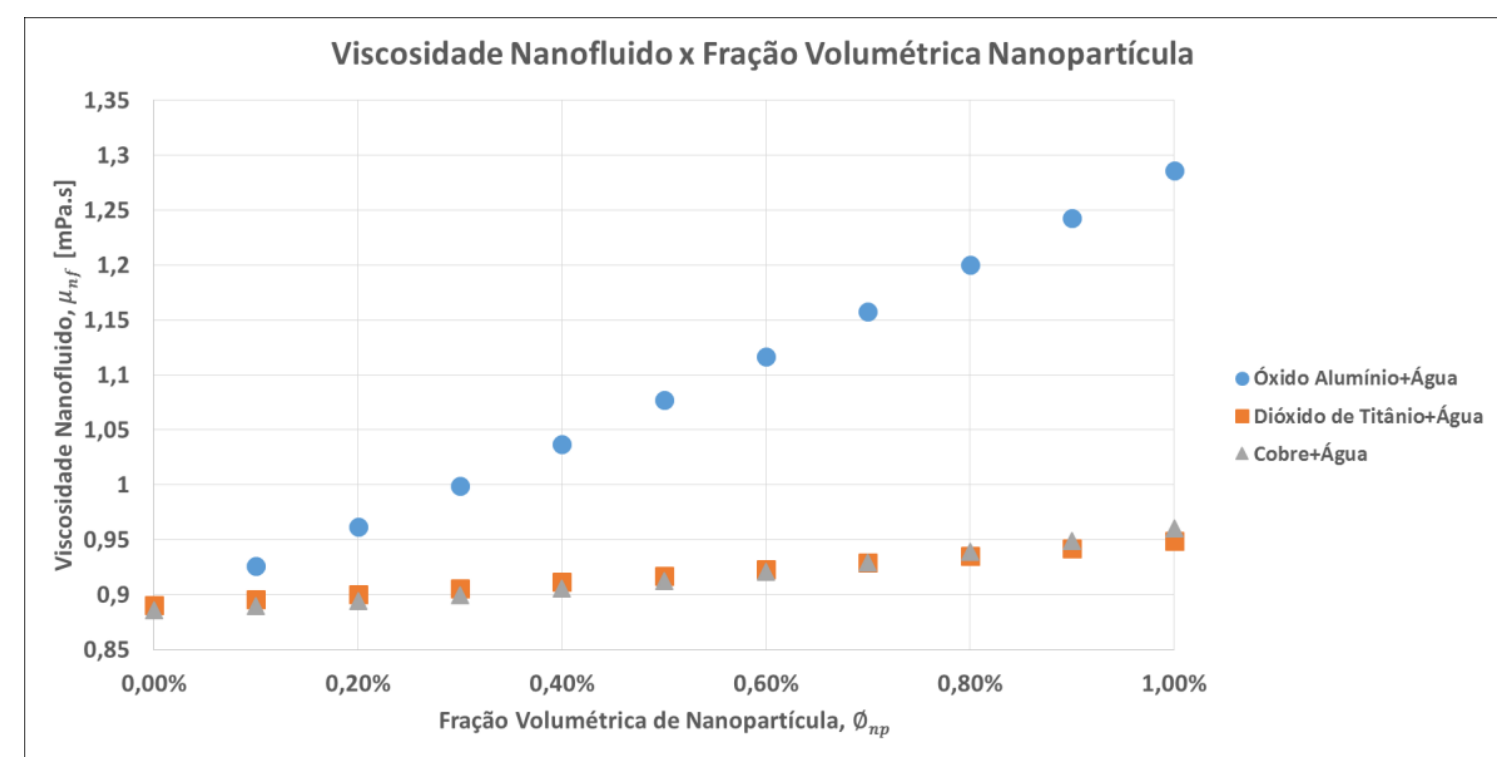

Figura 6.2 - Gráfico de Resultado: Viscosidade dos Nanofluidos

Como esperado, observa-se leve acréscimo na viscosidade das misturas com adição das nanopartículas e aumento de sua concentração volumétrica. 


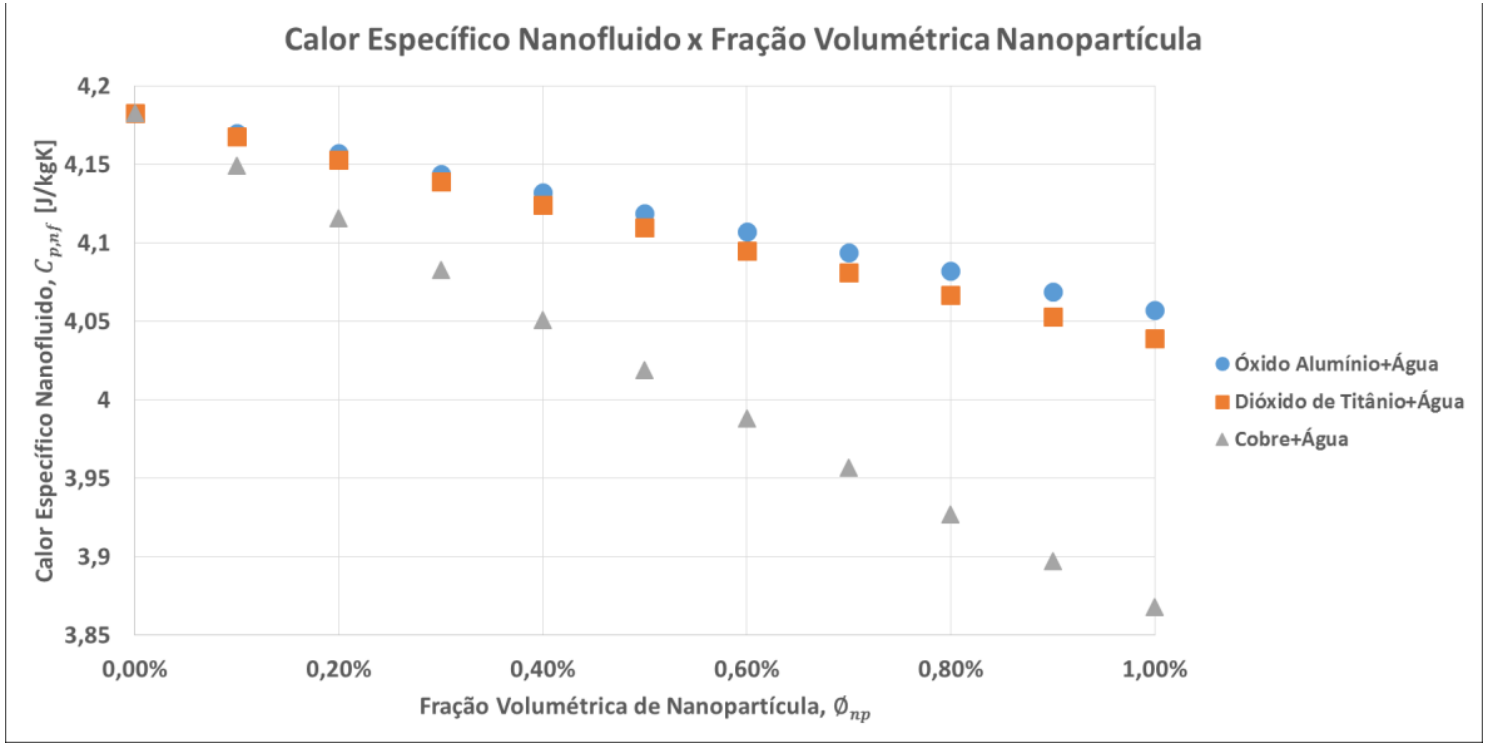

Figura 6.3 - Gráfico de Resultado: Calor Específico dos Nanofluidos

Queda no valor do calor específico das misturas, que pode ser explicado pelo aumento da densidade com adição das nanopartículas, de acordo com o modelo matemático adotado.

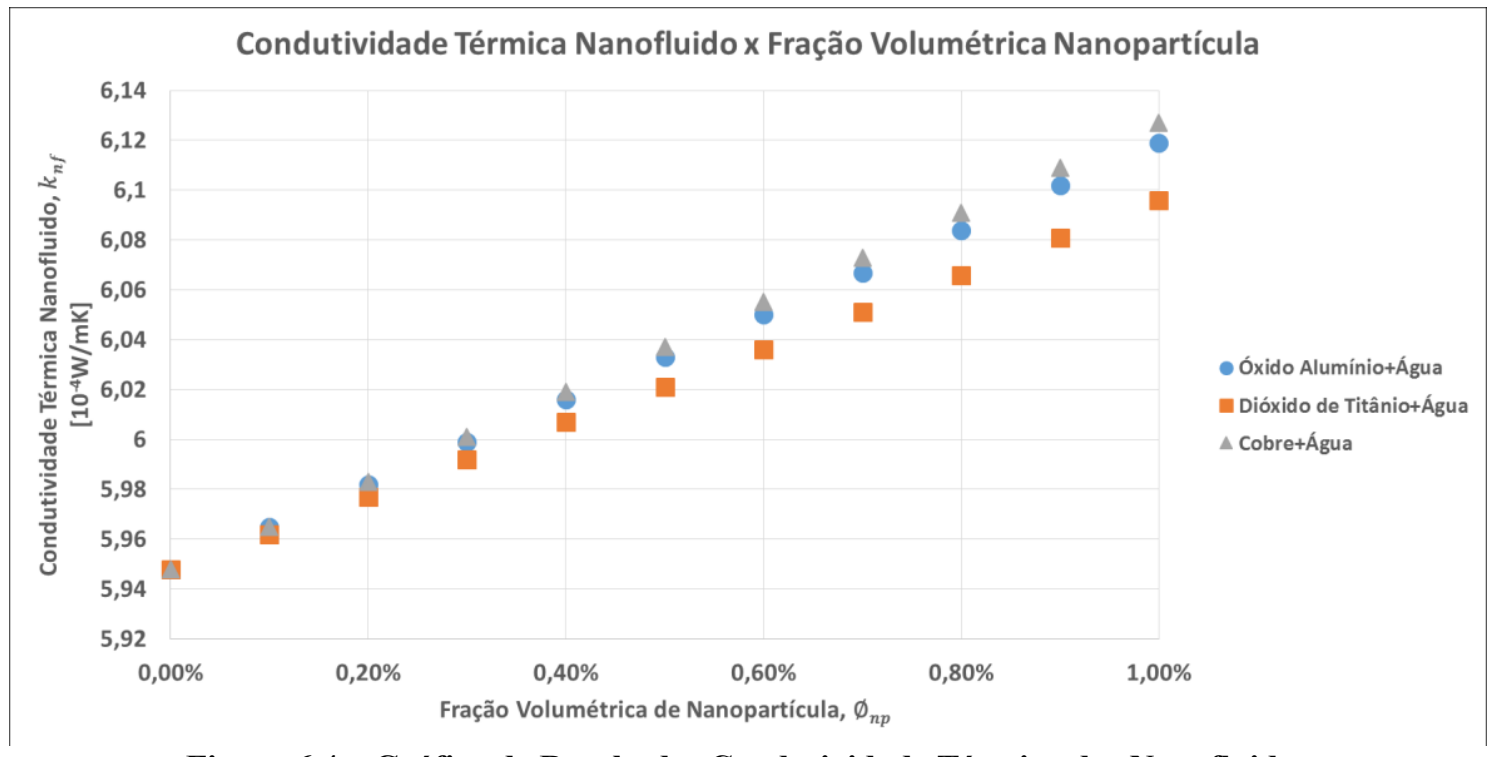

Figura 6.4 - Gráfico de Resultado: Condutividade Térmica dos Nanofluidos

Como esperado, observa-se acréscimo na condutividade térmica das misturas com adição das nanopartículas e aumento de sua concentração volumétrica. 


\subsubsection{Taxa de transferência de calor no Condensador}

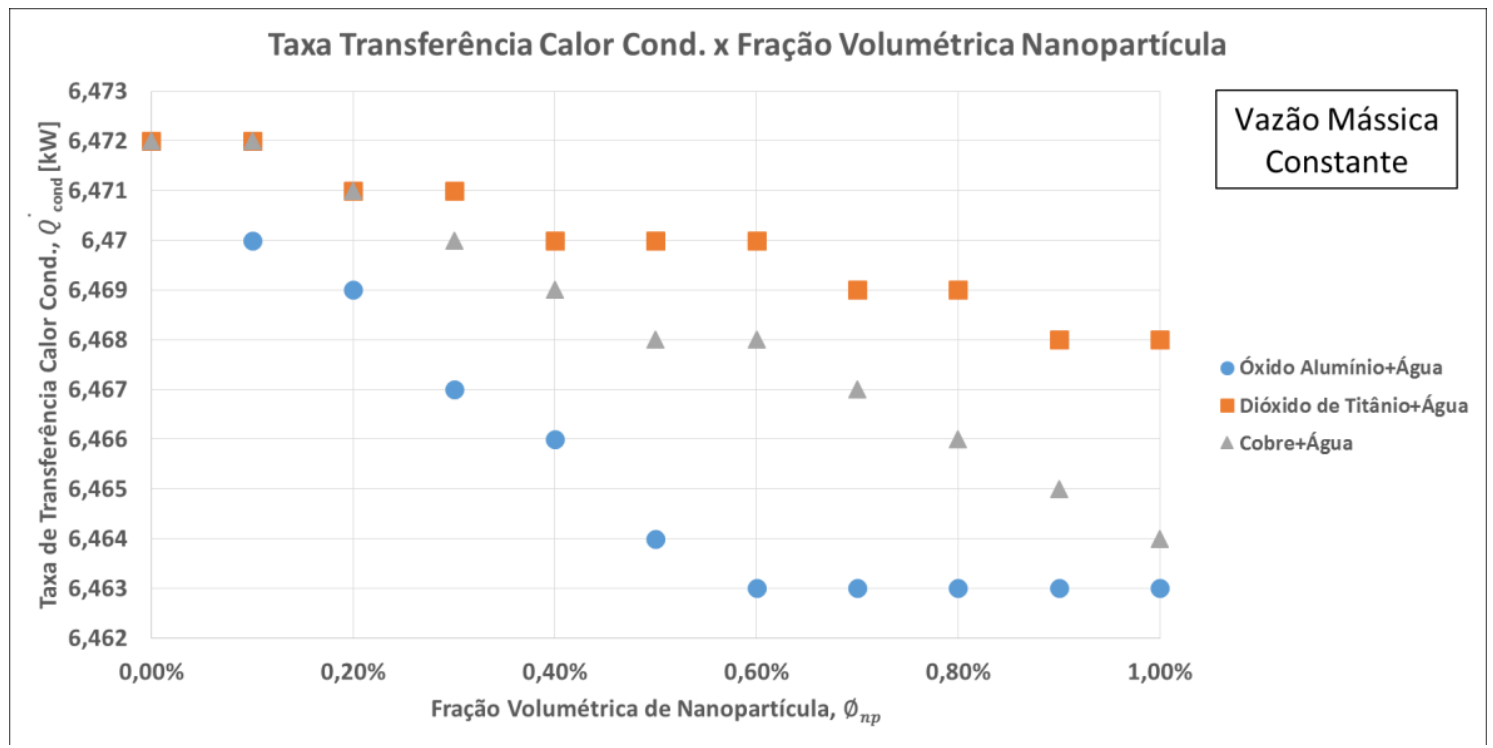

Figura 6.5 - Gráfico de Resultado: Taxa de Transferência de Calor, vazão mássica constante

Neste caso, com aumento da densidade e viscosidade, o número de Reynolds diminui consideravelmente, o que prejudica a troca de calor no condensador.

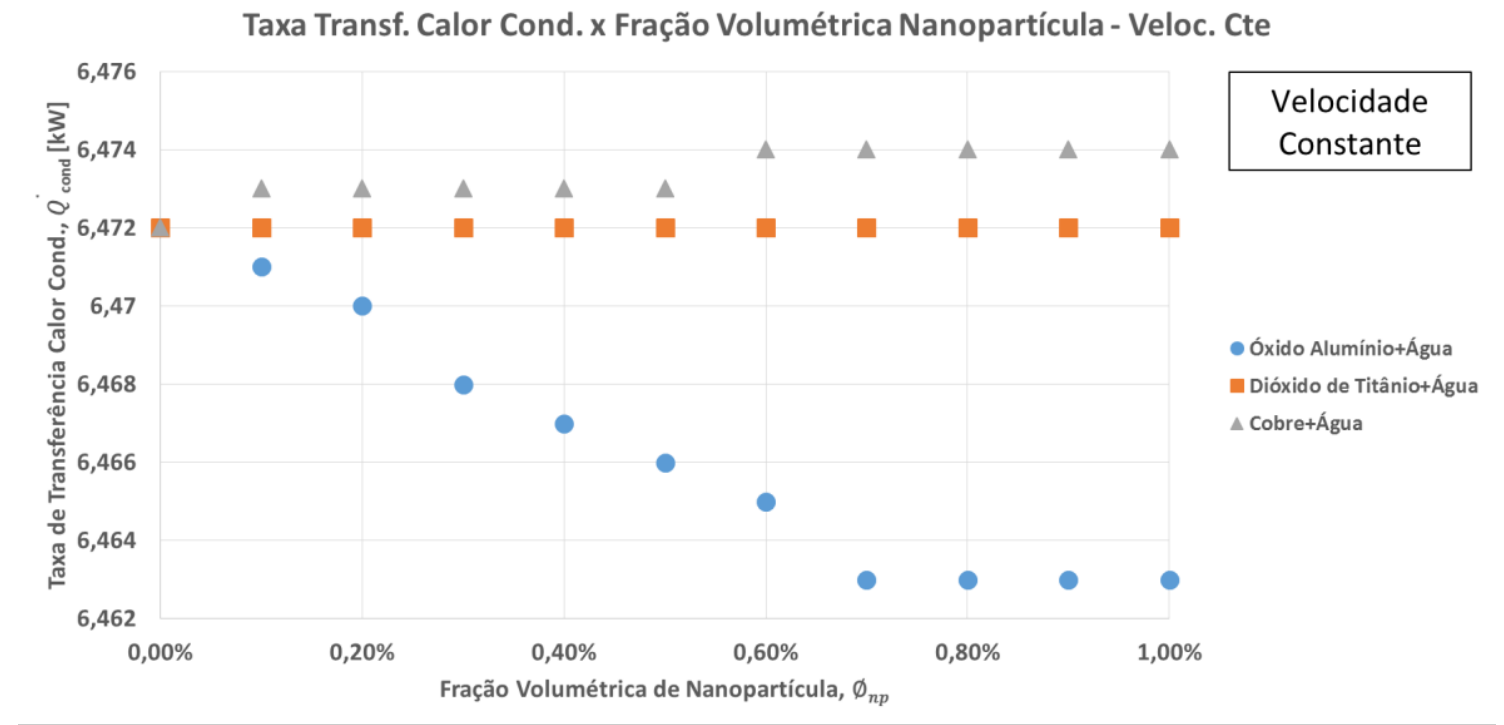

Figura 6.6 - Gráfico de Resultado: Taxa de Transferência de Calor, velocidade constante

Neste caso, foi calculada nova vazão mássica em busca da manutenção da velocidade do caso anterior. É possível observar sensível melhora em dois dos nanofluidos considerados. 


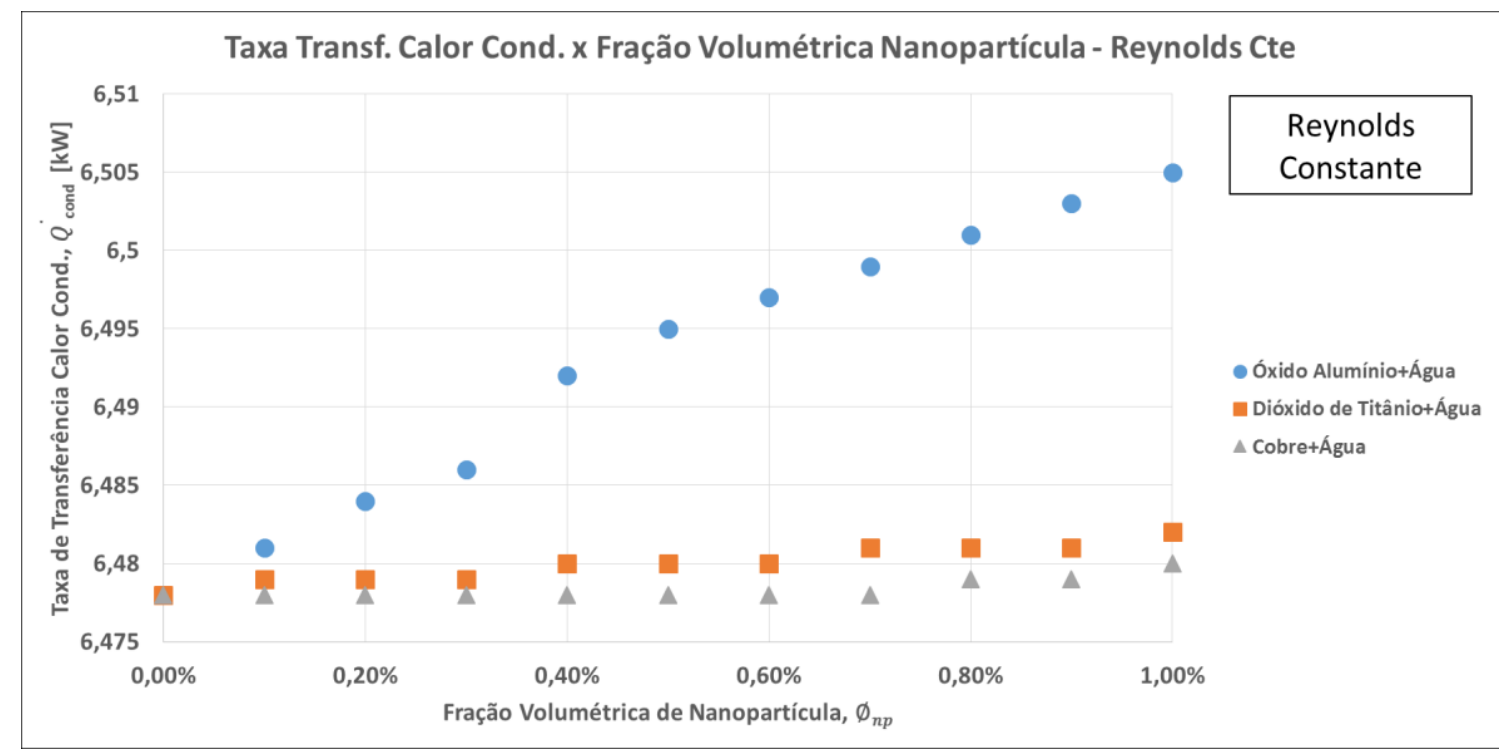

Figura 6.7 - Gráfico de Resultado: Taxa de Transferência de Calor, Reynolds constante

Neste caso, foi calculada nova vazão mássica em busca da manutenção do número de Reynolds do primeiro caso. É possível observar sensível melhora nos três nanofluidos considerados.

\subsubsection{Queda de Pressão no Condensador}

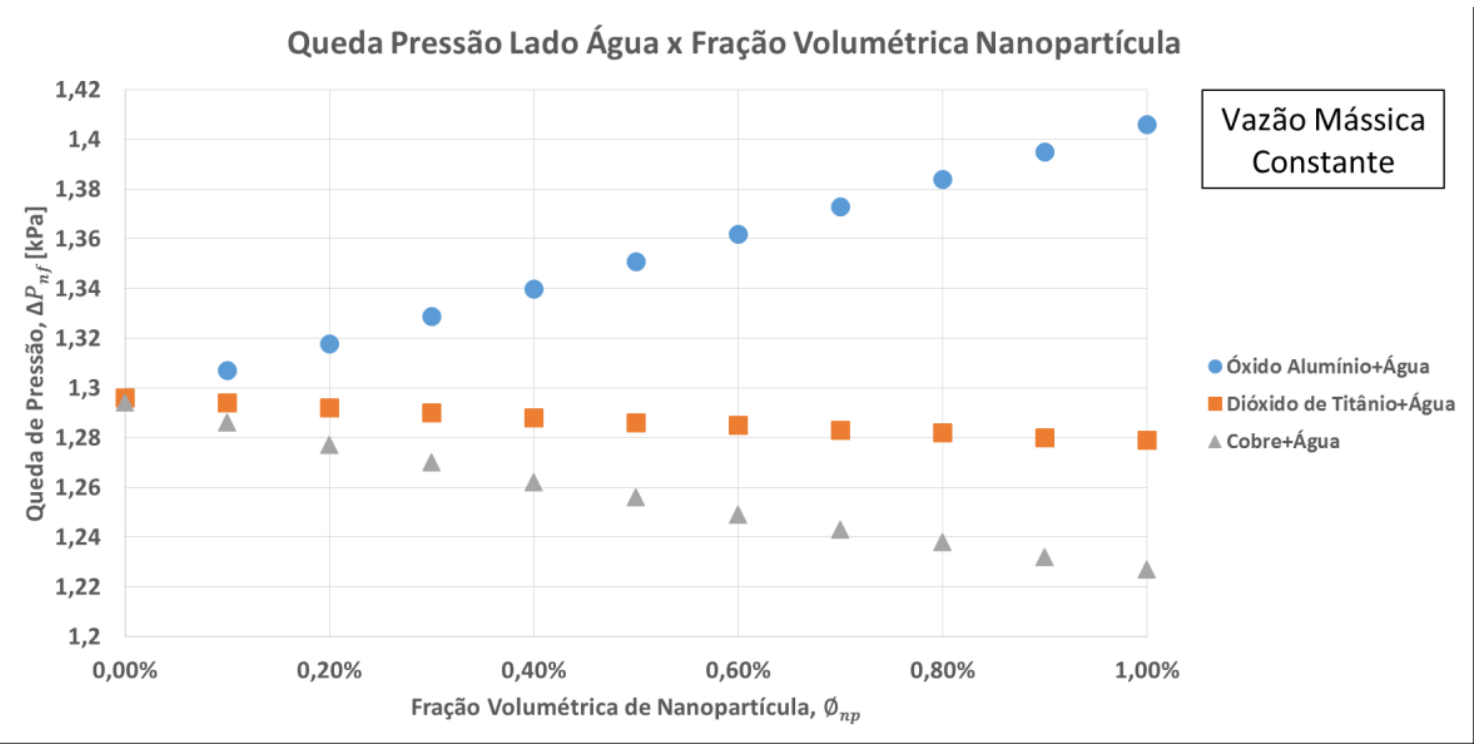

Figura 6.8 - Gráfico de Resultado: Queda de Pressão, vazão mássica constante 
Neste caso, mesmo com a diminuição do número de Reynolds, o aumento da densidade e viscosidade, fazem variar a queda de pressão.

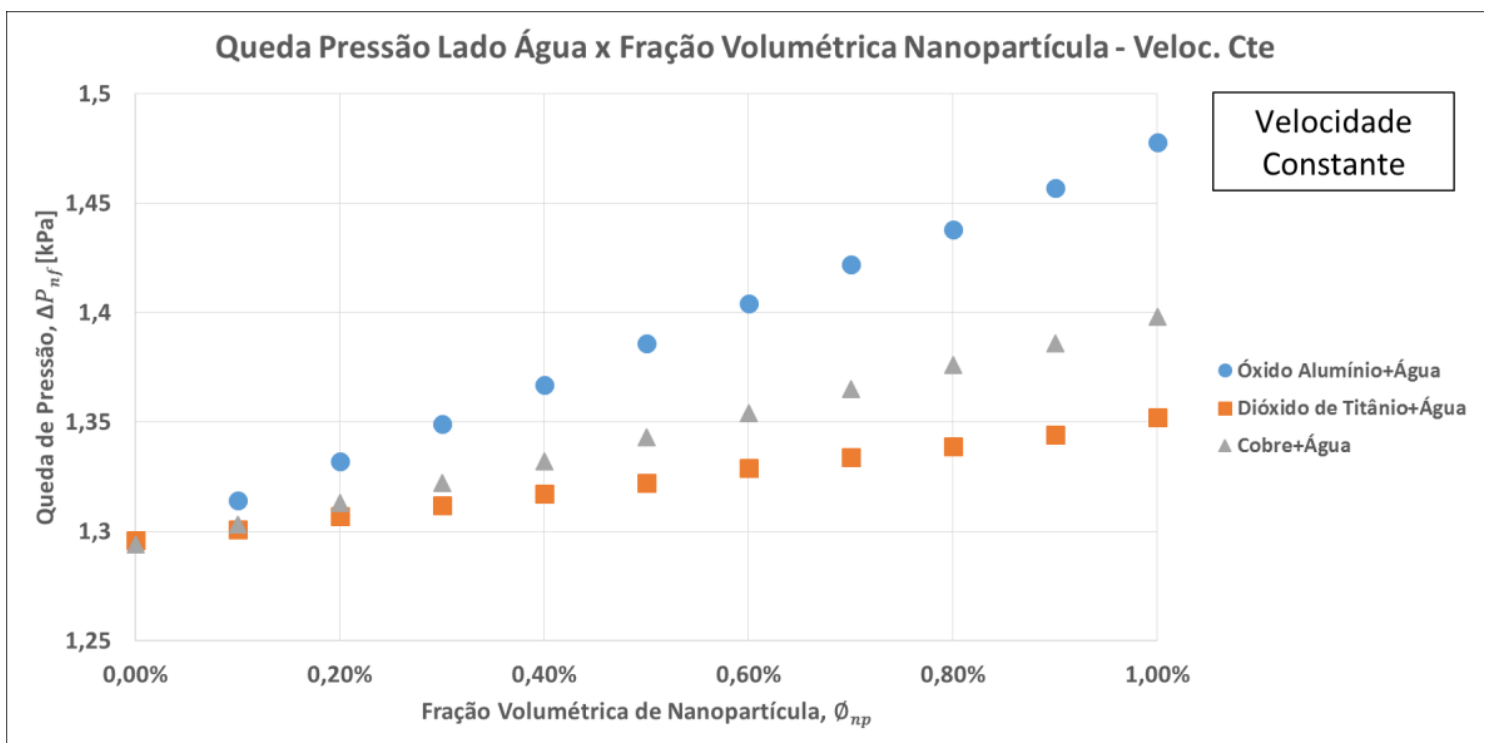

Figura 6.9 - Gráfico de Resultado: Queda de Pressão, velocidade constante

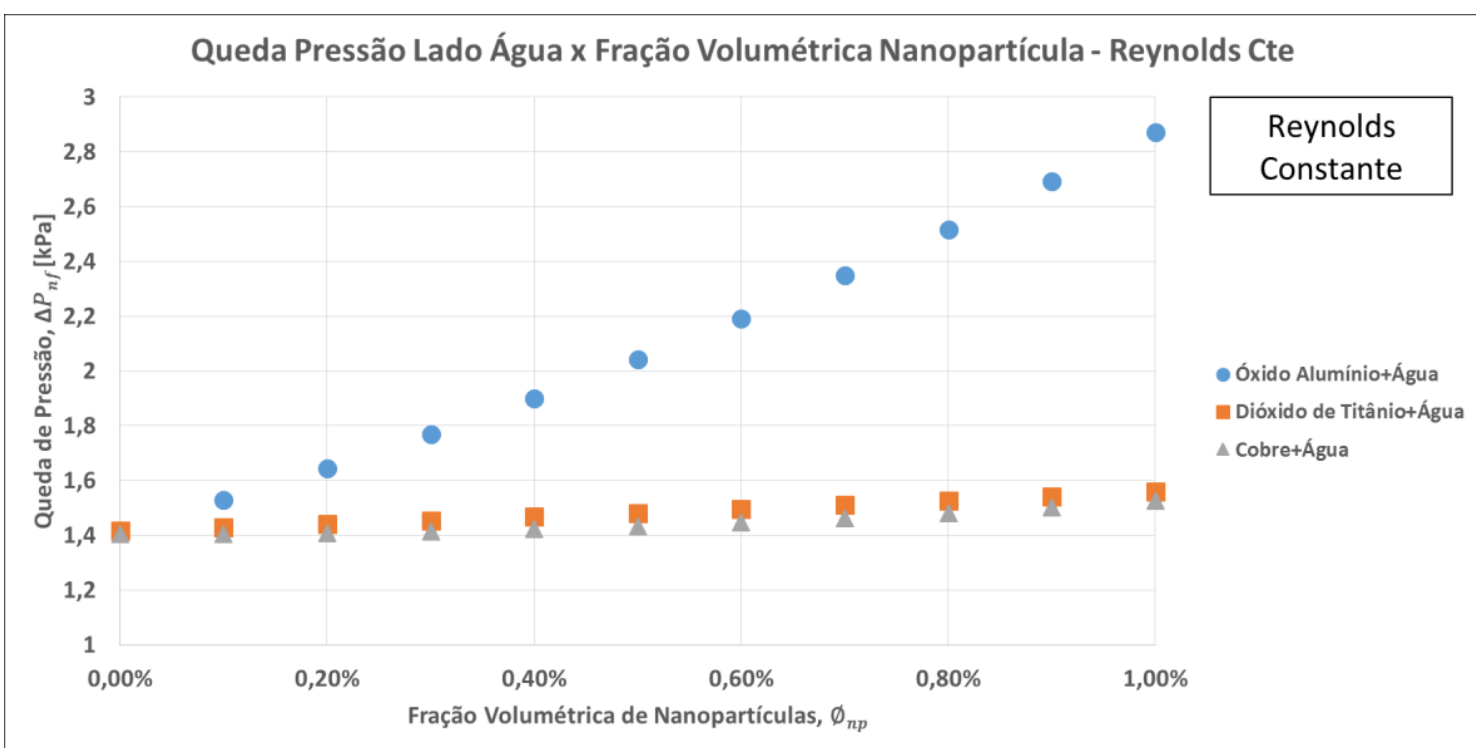

Figura 7 - Gráfico de Resultado: Queda de Pressão, Reynolds constante

Nos dois casos anteriores, observa-se que com maior vazão mássica, desenvolvem-se maior velocidade e número de Reynolds, aumentando consideravelmente a queda de pressão, principalmente quando foi considerado o óxido de alumínio. 


\section{Conclusão}

Com o presente trabalho foi possível aprimorar e validar um modelo matemático preexistente para um sistema trocador de calor considerando um condensador do tipo casco e tubo aletado. No modelo original foram inseridas novas equação, como por exemplo para o cálculo da perda de carga no lado da água. Foi possível também testar o modelo do condensador atuando em conjunto com uma sub-rotina para a modelagem das propriedades termofísicas de nanofluidos. Os resultados mostram que as variações nas propriedades observadas são relativamente restritas, o que está de acordo com o modelo adotado na sub-rotina, respeitando-se o intervalo de fração volumétrica considerado para este trabalho. O nanofluido composto por óxido de alumínio e água, foi o que mais aumentou a taxa de troca de calor no condensador, em contrapartida foi o que mais aumentou a queda de pressão em seu escoamento. Os resultados obtidos mostram que o uso de simulações numéricas e o modelo proposto para a análise de trocadores de calor se mostra eficaz e necessária, tendo em vista que é possível operar diversos casos, com diversos parâmetros e situações diferenciadas. 


\section{Bibliografia}

1- BANDARRA FILHO, E. P.; RIBATSKI, G.; PASSOS, J. C.; PARISE, J. A. R. Escoamento monofásico de nanofluidos no interior de tubos. In: Brazilian Congress of Thermal Engineering and Sciences, 12, 2008. Belo Horizonte. p. 1 - 10.

2- Briggs, D.E., - "Modified Wilson Plot Techniques for Obtaining Heat Transfer Correlations for Shell and Tube Heat Exchangers", Chemical Engineering Progress Symposium Series, 1969, p. 35-45.

3- Campos, R.V.C., "Modelagem do Uso de Nanofluidos no Sistema de Arrefecimento de Motores a Combustão Interna", Outubro 2009

4- Cuevas, C., - "Development And Validation Of A Condenser Thress Zones Model", Applied Thermal Engineering, Junho 2009, p. 3542-3543.

5- DAS, S. K.; CHOI, S. U. S.; YU, W.; PRADEEP, T. Nanofluids: Science and technology. Nova Jersey: John Wiley \& Sons, Inc., 2008. 397p.

6- DIAMOND, S. Annual progress report for heavy vehicle systems optimization. Washington: DOI - FreedomCAR and Vehicle Technologies Program, 2005, 206p.

7- Farrel, P., - "Heat Transfer and Friction Characteristics of Turbulator Radiator Tubes", SAE, 1991, p. 218-230.

8- KULKARNI, D. P.; DAS, D. K.; CHUKWU, G. A. Temperature dependent rheological property of copper oxide nanoparticles suspension (nanofluid). Journal of Nanoscience and Nanotechnology, v. 6, n. 4, p. 1150-1154, abr. 2006.

9- VELAGAPUDI, V.; KONIJETI, R. K.; ADURU, C. S. K. Empirical correlations to predict thermophysical and heat transfer characteristics of nanofluids.

10-WITHARANA, S. Boiling of refrigerants on enhanced surfaces and boiling of nanofluids. 